\title{
Research On Drilling CFRP Laminate With A Thin Woven Glass Fiber Surface Layer Using Plane Rake Faced Twist Drill
}

Liping Liu ( $\sim$ liuliping_tj@163.com )

Civil Aviation University of China

Bo Lian

Civil Aviation University of China

Changgeng Zhou

China Academy of Aeronautic Manufacturing Technology

Kehao Duan

Civil Aviation University of China

Xueming Zhu

Tianjin University of Technology and Education

\section{Pingfeng Xia}

Tianjin Weikende Measurement and Control Equipment Technology Company

\section{Research Article}

Keywords: CFRP, Plane rake faced twist drill, Reference rake angle, Thrust force, Drilling damage

Posted Date: May 18th, 2021

DOl: https://doi.org/10.21203/rs.3.rs-389824/v1

License: (9) (i) This work is licensed under a Creative Commons Attribution 4.0 International License. Read Full License

Version of Record: A version of this preprint was published at The International Journal of Advanced Manufacturing Technology on August 12th, 2021. See the published version at https://doi.org/10.1007/s00170-021-07796-8. 


\title{
Research on drilling CFRP laminate with a thin woven glass fiber surface layer using plane rake faced twist drill
}

\author{
Liping Liu ${ }^{*} \cdot$ Bo Lian $^{1} \bullet$ Changgeng Zhou ${ }^{2} \cdot$ Kehao Duan $^{1} \cdot$ Xueming Zhu ${ }^{3} \bullet$ Pingfeng Xia
}

\begin{abstract}
The delamination produced during drilling CFRP will affect its structural strength seriously. Delamination is closely related to the thrust force during drilling, which is closely related to the tool, so it is particularly important to choose the tools with appropriate geometric structure. Many scholars used tools with different geometric structure to drill CFRP, and then conducted the drilling damage analyses and drilling mechanism researches. It finally came to a conclusion that drill with special structure had certain advantage compared with common twist drill in the drilling process. In this paper, a new type of plane rake faced twist drill was used to drill the CFRP laminate with a thin woven glass fiber surface layer. Experimental results showed that plane rake faced twist drill along cutting edge had a constant reference rake angle value, which caused the plane rake faced twist drill generated smaller thrust force and less drilling damage than the common twist drill. As the reference rake angle of plane rake faced twist drill increased, the thrust force and drilling damage decreased. It was revealed the inhibition of the thin woven glass fiber surface layer on the drilling damage at entrance and exit. Finally, it was proposed that when plane rake faced twist drill was used to drill CFRP laminate with a thin woven glass fiber surface, $46^{\circ}$ reference rake angle should be selected.
\end{abstract}

Keywords CFRP . Plane rake faced twist drill · Reference rake angle $\cdot$ Thrust force $\cdot$ Drilling damage

\section{Introduction}

Carbon fiber reinforced polymer(CFRP) composite is an excellent structural composite material which composed of high-strength carbon fiber and flexible matrix material. Carbon fiber composite materials have high strength-to-weight ratio and stiffness constitute,

\footnotetext{
* Liping Liu

E-mail address:liuliping_tj@163.com(Liping Liu).
}

${ }^{1}$ School of Aerospace Engineering, Civil Aviation University of China, Tianjin 300300, China

${ }^{2}$ Composite Materials Technology Center, China Academy of Aeronautic Manufacturing

Technology,Beijing, 101300, China

${ }^{3}$ Faculty of Mechanical Engineering, Tianjin University of Technology and Education, Tianjin 300222, China

${ }^{4}$ Tianjin Weikende Measurement and Control Equipment Technology Company,Tianjin, 300356, China relatively low density, high damping capacity, great dimensional stability and strong corrosion resistance. Therefore, carbon fiber reinforced polymers have been widely used in many high-tech industries. In order to increase the thrust-to-weight ratio of civil aviation aircraft, the use of composite materials was increased in the fuselage to reduce its weigh while considering the strength, thereby improving economy. Carbon fibre reinforced plastics (CFRP) can and will in the future contribute more than $50 \%$ of the structural mass of an aircraft [1-3].

While carbon fiber reinforced polymer composite has various advantages, the cutting mechanism is quite different from traditional material cutting mechanism due to its anisotropy and high wear resistance. Therefore, the 
manufacturing processing of carbon fiber reinforced polymer composite has become the main reason for its limited application [4]. For traditional drilling carbon fiber reinforced polymer composite, there is damage such as interlayer delamination and uncut fibers, matrix melting, fiber cracks and so on, which make it particularly difficult to analyze its drilling performance [5]. In the composite material manufacturing industry, traditional drilling is the main method for making composite material holes. Holes need to be drilled during assembling the aircraft structure. The quality of assembly mechanical joints such as bolted connections, rivet connections and pin connections are highly dependent on the quality of drilling [6].

A large number of researchers had used different drilling tools to conduct experiments and analyzed the cutting performance of different tools and the machinability of CFRP. Some researchers mainly used different types of tools, such as brad \& spur drill, step drill and dagger drill, etc. for CFRP drilling experiments. These tools were quite different from common twist drills in terms of geometric structure, to a certain extent, they had better cutting performance. For example, brad \& spur drills showed excellent performance results during drilling fiber reinforced materials. Due to the cut-push effect (the drill first cuts the last layer of the composite, then pushes this layer off) of sharp flank cutting edges, the number of uncut fibers as well as delamination could be minimized [7]. The dagger drill (one-shot drill) was a special double point angle twist drill with four straight grooves. Compared with common twist drill, it had bigger thrust force. However, it exhibited better drilling performance than common twist drill. In other words, the damage area of burrs and delamination factor were lower [8]. The step drill was used to drill a pilot hole with a smaller diameter drill bit firstly and then a larger diameter cutting edge was used for reaming, so that the delamination effect of the chisel edge could be minimized, thereby achieving smaller drilling damage. Qiu et al. [9] used twist drills and step drills to conduct drilling experiments on CFRP. The effect of the ratio of the minimum diameter $D_{1}$ to the maximum diameter $\mathrm{D}$ of the step drill on the cutting force and the damage of the hole wall was studied. The results showed that step drills had better drilling performance than common twist drills and a smaller maximum thrust and damage area were produced on the hole wall.

Other researchers mainly used twist drills with different geometries to drill CFRP. For example, the twist drills with different chisel edge, drill point angle or rake face were used during drilling CFRP. Wang et al. [10]used the standard twist drill (ST), the drill with a shorter chisel edge and a larger point angle $\left(130^{\circ}\right)$ (SCE-LPA), the drill with a short S-shape chisel edge and a larger point angle $\left(130^{\circ}\right)$ (SSCE-LPA), along with the drill with double point angles $\left(90^{\circ}\right.$ and $\left.140^{\circ}\right)$ and a shorter chisel edge (SCE-DPA) to conduct drilling experiments. The research results showed that the tools with shorter chisel edge (SCE-LPA, SSCE-LPA, SCE-DPA) could provide smaller thrust force than the standard twist drills (ST), which could fully ensure better drilling quality. It was also verified that the conclusive factor of drilling quality was tool structure rather than diamond coating. The change to the point angle mainly referred to double point angle twist drills. When the first drill point angle was the same as that of the common twist drill, a smaller thrust force value and small delamination damage were 
produced, which was due to the double point angle twist drill had a smaller second drill point angle value. At the same time, they also had better wear resistance [11]. Therefore, the use of appropriate tools are particularly important to reduce the defects of drilling.

Until now, there are few researches studying on the twist drill with change rake face. Armarego et al. [12] proposed the way to obtain one new type of plane rake faced twist drill by grinding the rake face of common twist drill. The tool had also been verified through experiments that it had better drilling performance than common twist drill, but this research mainly aimed at the drilling of aluminum alloy. There were few studies about the plane rake faced twist drill was used to drill CFRP laminate, the characteristic of low drilling damage is unknown. In this paper, the plane rake faced twist drills with different reference rake angle and a common twist drill were used to drill CFRP laminate with a thin woven glass fiber surface layer. The purpose was to study the characteristic of low drilling damage with the plane rake faced twist drill, and the influence of plane rake faced twist drills with different reference rake angle on the drilling quality at the drilling entrance and exit of CFRP laminate with a thin woven glass fiber surface layer. In addition, the effect of the thin woven glass fiber on the drilling damage at the entrance and exit of the drilling hole was disclosed.

\section{Geometrical analysis of drilling tool}

The plane rake faced twist drill is shown in Figure 1. In the design of this kind drill, common twist drill were modified by grinding a plane rake face on each rake face with a disc shaped grinding wheel. During grinding, the reference rake angle at the outer corner of lip was used as the benchmark to make the entire cutting edge produce a constant reference rake angle. The reference rake angle at each point along the cutting edge is defined as: projection in a plane normal to the lip of the angle between a plane parallel to the drill axis containing the lip and tangent to the flute surface at the point in question. The plane parallel to the axial direction and containing the cutting edge is called $\mathrm{P}_{\mathrm{f}}$, and the tangential plane of the helix surface at different points on the cutting edge is called $\mathrm{P}_{\mathrm{h}}$. The plane $\mathrm{P}_{\mathrm{f}}$ of different points on the cutting edge is the same and unchanged. As the radius increasing, the helix angle of the common twist drill gradually increases, and the plane $P_{h}$ changes, so that the angle between the plane $\mathrm{P}_{\mathrm{f}}$ and the plane $\mathrm{P}_{\mathrm{h}}$ in the normal plane $\mathrm{P}_{\mathrm{n}}$ increases at each point. It means that the reference rake angle gradually increases along the cutting edge. When the common twist drill is grinded to a plane rake face twist drill, the plane $\mathrm{P}_{\mathrm{h}}$ of each point on the cutting edge coincides, so that there is a constant reference rake angle at different radius of the main cutting edge.

The width of the plane rake face of grinding is subjected to certain restrictions. On the one hand, when the width of the ground plane rake face is over large, the strength of cutting edge will decrease and the life span of tool will be sharply reduced. On the other hand, if the width of the plane rake face is too small, the cutting performance is not excellent enough. Therefore, the width of the plane rake face is determined by considering the contact length between the tool and the chip, rather than significantly reducing the cutting edge strength. For smooth chip disposal, the width $\mathrm{Y}$ of the plane rake face should be larger than the maximum tool-chip contact length $h_{\max }$ [13]. 
Fig.1 Geometry of a plane rake faced drill.

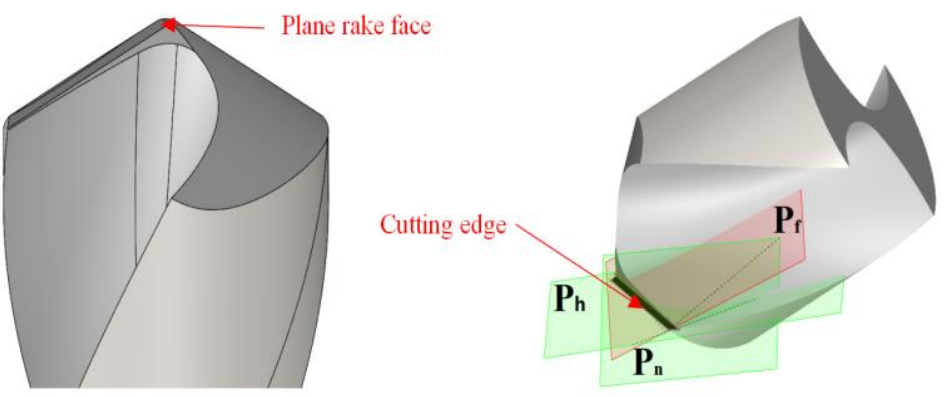

Fig.2 Geometrical relationship between

various "fundamental" and specified

drill angles at the lips of a plane rake

faced drill

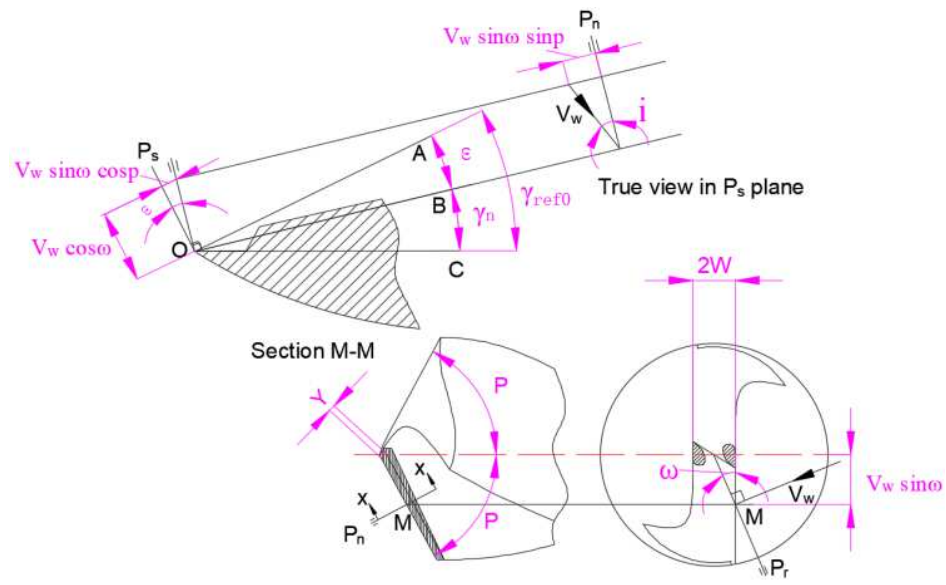

$$
h_{\max }=\frac{t}{0.6}
$$

where $t$ is the undeformed chip thickness. In the lip region of a drilling operation, $t$ can be given by [14]

$$
t=\frac{f \cdot \sin p \cdot \cos \varepsilon}{2}
$$

$f$ represents the feed per revolution, which is related to the speed and feed. $P$ represents the half drill point angle. $\varepsilon$ represents the velocity angle.

\subsection{Fundamental geometry on the lips}

Fig. 2 shows the geometrical relationships between various fundamental drill angels at one lip of a plane rake faced drill. $\mathrm{P}_{\mathrm{r}}$ represents the reference plane of point $\mathrm{M}, \mathrm{P}_{\mathrm{s}}$ represents the cutting plane, $\mathrm{P}_{\mathrm{n}}$ represents the normal plane of point $M$. In addition, OA represents the intersecting line of the plane $\mathrm{P}_{\mathrm{f}}$ and the normal plane $\mathrm{P}_{\mathrm{n}}, \mathrm{OB}$ represents the intersecting line of the plane $\mathrm{P}_{\mathrm{r}}$ and the normal plane $\mathrm{P}_{\mathrm{n}}$, OC represents the intersecting line of the plane rake face and the normal plane $\mathrm{P}_{\mathrm{n}}$. According to the definition of reference rake angle, the included angle between OA and OC mean reference rake angle. The normal rake angle is defined as the projection of reference plane and rake face on normal plane, that is, the included angle between $\mathrm{OB}$ and $\mathrm{OC}$. It can be given by the following formula:

$$
\gamma_{n}=\gamma_{r e f}-\varepsilon=\gamma_{r e f o}-\varepsilon
$$

$\varepsilon$ represents the velocity angle, which is defined as: the angle between the work velocity and the normal to a plane parallel to the drill axis containing the lip, projected in a plane normal to the lip. According to the geometric relationship in Figure 2, it is equivalent to the angle between $\mathrm{OA}$ and $\mathrm{OB}$, which can be expressed by the following formula:

$$
\tan \varepsilon=\frac{V_{w} \cdot \sin \omega \cdot \cos p}{V_{w} \cdot \cos \omega}=\tan \omega \cdot \cos p
$$

Where $\omega$ is the web angle at point $\mathrm{M}$ with 
radius $r, W$ represents the half of the drill web

thickness and is given by:

$$
\omega=\sin ^{-1}\left(\frac{W}{r}\right)
$$

$i$ represents the inclination angle, which is the included angle between the normal plane and the cutting speed $V_{\mathrm{w}}$ in the cutting plane. It is given by

$$
i=\sin ^{-1}(\sin \omega \cdot \sin p)
$$

From formulas (3), (4) and (5), it can be seen that as the increase of radius, the web angle $\omega$ gradually decreases. As the decrease of the web angle $\omega$, the velocity angle $\varepsilon$ also decreases, which leads to an increase in the normal rake angle. The reference rake angle of common twist drill along the lip can be by [14]

$$
\gamma_{r e f}=\tan ^{-1}\left(\frac{\tan \delta \cdot \cos \omega}{\sin p-\tan \delta \cdot \sin \omega \cdot \cos p}\right)
$$

Where $\delta$ represents the helix angle of each point on the cutting edge. The helix angle of common twist drill gradually increases as the radius of the main cutting edge increasing. That is, the reference rake angle increases as the radius of the main cutting edge increasing, and so does the normal rake angle. But when the plane rake faced drill is produced after grinding the curved rake face to a plane rake face, the helix angle $\delta$ at each point is equal to the helix angle $\delta_{0}$ at the outsider diameter. At the same time, the reference rake angle $\gamma_{\text {ref }}$ is also equal to the reference rake angle at the outer corner of lips $\gamma_{\text {refo }}$, that is, $\delta=\delta_{0}, \gamma_{\text {ref }}=\gamma_{\text {refo }}$. Finally, the normal rake angle of each point on the cutting edge of the plane rake faced twist drill is larger than that of the common twist drill.

\section{Drilling experiment}

\subsection{Experiment set up}

The experiment was carried out on $\mathrm{CNC}$ machine tool (model: JTMT-CK6136). The mobile platform of CNC machine tool provided movement in $\mathrm{X}$ and $\mathrm{Z}$ directions. The precision moving platform was installed on $\mathrm{CNC}$ machine tool and the movement of clamped material in $\mathrm{Y}$ direction was controlled by the corresponding controller, so the movement of material in three directions was satisfied. The thrust force was measured through a strain dynamometer installed on the back of material. A data capture system including amplifier, data display and data analysis software was used to collect thrust force signals. The tool was fixed on a high-speed main spindle at the end of CNC machine tool and the speed was precisely controlled by frequency converter. The entire experimental platform is shown in Figure 3. After drilling, an optical microscope and an electron microscope (model:Hitarchi S-3400N) were used to observe the surface morphology of drilling hole entrance and exit.

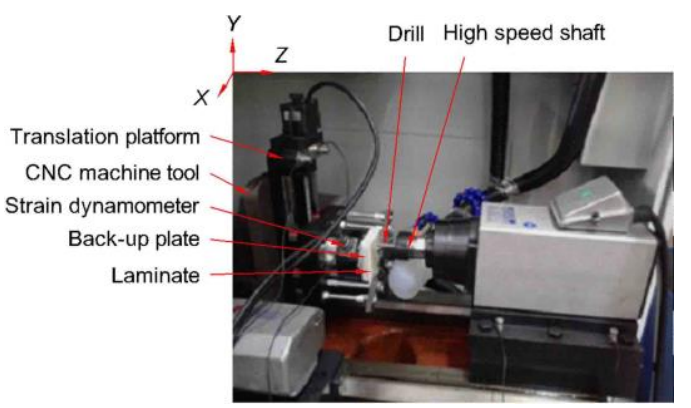

Fig.3 Experiment platform.

\subsection{Workpiece material and drilling tools}

In this paper, the CFRP laminate with thin woven glass fiber surface layer was similar to that used in literature [15]. The uppermost and the lowermost layers of CFRP laminate had woven glass fibers layers with the thickness of $0.09 \mathrm{~mm}$. The laying sequence is shown in Figure 4 and the size is $75 \mathrm{~mm} \times 65 \mathrm{~mm} \times 6.18 \mathrm{~mm}$. 
The main parameters of internal carbon fiber laminate are shown in Table 1.

Table 1 Carbon fiber-reinforced plastic.

\begin{tabular}{lc}
\hline Parameters & Values \\
\hline & {$\left[0^{\circ}-45^{\circ} 90^{\circ}\right.$} \\
Laying & $\left.45^{\circ}\right] 5 \mathrm{~s}$ \\
Fiber density & $1.81 \mathrm{~g} / \mathrm{cm}^{3}$ \\
Fiber volume fraction & $65 \%$ \\
Thickness & $6 \mathrm{~mm}$ \\
\hline
\end{tabular}

Table 2 Geometric angles for plane rake faced twist drills and common twist drill.

\begin{tabular}{|c|c|c|}
\hline No. of drill & $\gamma_{\text {refo }}$ & Drill \\
\hline $\mathrm{T}_{1}$ & $30^{\circ}$ & \\
\hline $\mathrm{T}_{2}$ & $26^{\circ}$ & \\
\hline $\mathrm{T}_{3}$ & $30^{\circ}$ & \\
\hline $\mathrm{T}_{4}$ & $34^{\circ}$ & \\
\hline $\mathrm{T}_{5}$ & $38^{\circ}$ & \\
\hline $\mathrm{T}_{6}$ & $42^{\circ}$ & \\
\hline $\mathrm{T}_{7}$ & $46^{\circ}$ & \\
\hline $\mathrm{T}_{8}$ & $50^{\circ}$ & \\
\hline
\end{tabular}

In this paper, one common twist drill and seven plane rake faced twist drills with different reference rake angle at the outer corner of lips were used to drill CFRP laminate with thin woven glass fiber surface layer. The tools were numbered, as shown in Table 2. The reference rake angle at the outer corner of lips of common twist drill is $30^{\circ}$, and that of seven plane rake faced twist drills are range from $26^{\circ}$ to $50^{\circ}$. Except for reference rake angle at the outer corner of lips, other geometric parameters were the same, such as the half point angle $P=60^{\circ}$, diameter $d=6 \mathrm{~mm}$ and clearance angle $\alpha=30^{\circ}$. In the process of drilling, the speed was $2000 \mathrm{rpm}$, and the feed was $100 \mathrm{~mm} / \mathrm{min}$.
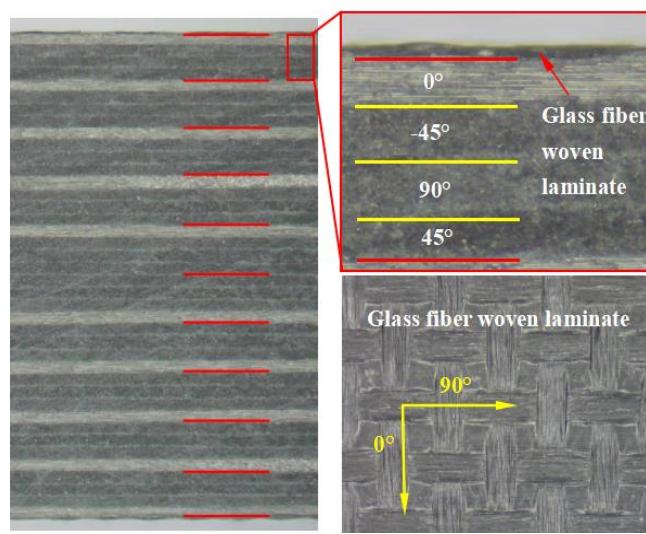

Fig.4 Layer morphology.

\subsection{Damage factor}

In this paper, delamination factor was defined as the ratio of maximum diameter $\left(D_{\max }\right)$ of drilled hole surface damage area to the standard diameter of drilled hole $(D)$, which was traditional delamination damage factor $\left(F_{a}\right)$ as shown in Figure 5. The optical microscope was used to accurately compare the delamination factor among the holes drilled by different tools. The traditional delamination damage factor is shown in equation (8).

$$
F_{a}=\frac{D_{\max }}{D}
$$




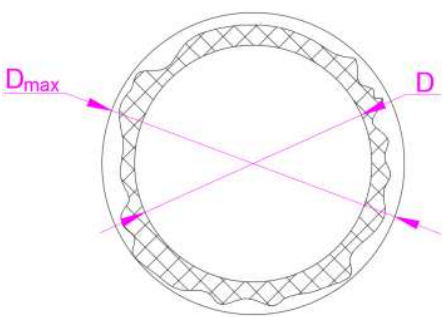

Fig.5 Delamination damage factor.

\section{Results and discussion}

\subsection{Thrust force analysis}

The rake face of common twist drill was changed from curved to plane through grinding, resulting in the generation of plane rake faced twist drill. The main cutting edge of plane rake faced twist drill could be regarded as many micro-elements of inclined cutting. The inclination angles at each point of plane rake faced twist drill were the same as that of common twist drill before grinding [14]. The forces of plane rake faced twist drill and common twist drill were similar. As shown in Figure $6, F_{\text {th }}$ represents total thrust force. $F_{\text {chith }}$ represents the thrust force generated by chisel edge. $F_{\text {lipth }}$ represents the thrust force generated by main cutting edge. The relationship between them is as follows:

$$
F_{\text {th }}=F_{\text {chith }}+F_{\text {lipth }}
$$

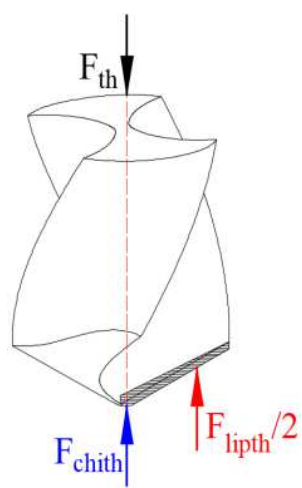

Fig.6.Thrust force distribution of plane rake faced twist drill.

Each tool was tested twice under the same parameters and the average value of two test results was calculated. The thrust force value for each experiment was the average of thrust force when the main cutting edge was steadily drilling. The typical thrust force signals recorded during drilling is shown in Figure 7. Fig. 7(a) is a typical thrust force signal during drilling with a common twist drill whose reference rake angle at the outer corner of lips is $30^{\circ}$. Figure 7(b) is a typical thrust force signal during drilling with a plane rake face twist drill whose reference rake angle at the outer corner of lips is $30^{\circ}$.

Comparing the plane rake faced twist drill with common twist drill, it could be seen from Figure 7(b) that the thrust force increased to a smaller value $B_{1}$ firstly, and then it steadily increased to peak value $B_{2}$ when the entire main cutting edge participated in drilling. However, when the chisel edge of a common twist drill participated in drilling, the thrust force increased to a larger value $A_{1}$. Then the main cutting edge of a common twist drill gradually participated in drilling, the thrust force unsteadily increased to a larger peak value $A_{2}$. The reason for the different drilling process between plane rake faced twist drill and common twist drill was that reference rake angles of common twist drill along the main cutting edge changed. While, the reference rake angles of plane rake faced twist drill along the main cutting edge were constant. So the thrust force curve of common twist drill fluctuated obviously and there was an inflection point, as shown in Figure 7(a). However, the thrust force curve of plane rake faced twist drill was smooth. At the same time, plane rake face twist drill had a smaller thrust force peak $B_{2}$ than common twist drill. There were two main reasons for this. On the one hand, the chisel edge (near the main cutting edge) could be eliminated through grinding. During this process, it did not reduce the actual length and change the rake angle of 
chisel edge, so it is usually called "point relieving". This phenomenon had been proved to have a significant effect on reducing peak thrust force [14]. On the other hand, compared with common twist drill, plane rake faced twist drill had an larger reference rake angle at the same position of the main cutting edge. The increase of reference rake angle could reduce thrust force, and it could also improve the cutting performance of the tool during drilling CFRP laminate with thin woven glass fiber surface layer.
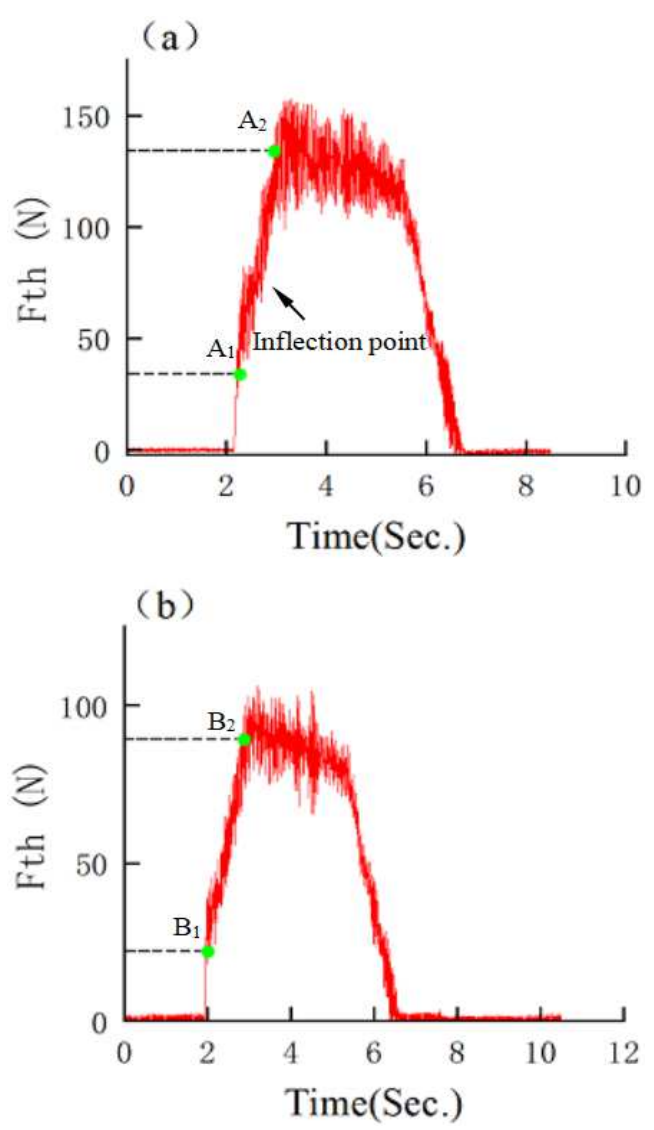

Fig.7. Typical thrust forces signals recorded during drilling. (a) common twist drill with $30^{\circ} \gamma_{\text {refo }}$. (b) plane rake faced twist drill with $30^{\circ} \gamma_{\text {refo. }}$.

For plane rake faced twist drills with different reference rake angles, the thrust force and the thrust force decreasing amplitude are shown in Figure 8. The decreasing amplitude is calculated by the following formula:

$$
d_{n+1}=\frac{F_{n}-F_{n+1}}{F_{n}} \times 100 \%
$$

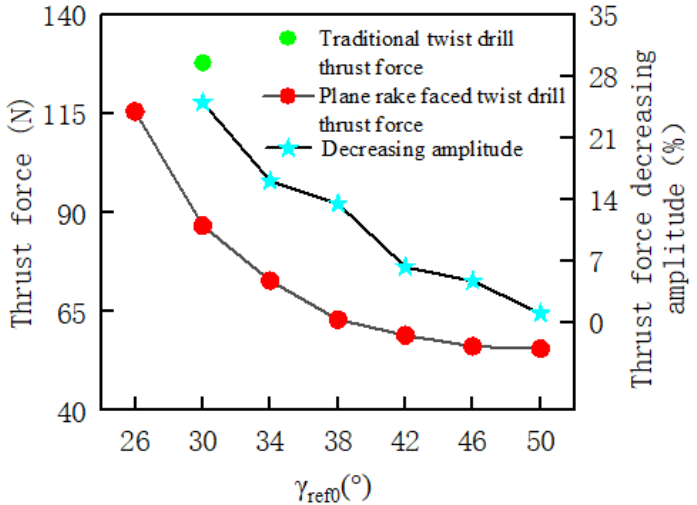

Fig.8 Thrust force values and decreasing amplitude with different plane rake faced twist drills.

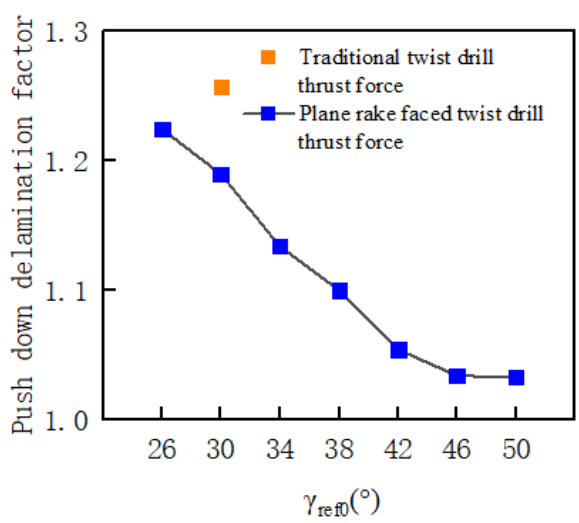

Fig.9. Push down delamination factors with different plane rake faced twist drills.

Where $d_{\mathrm{n}+1}$ represents the decreasing amplitude about thrust force of tool No. $\mathrm{T}_{\mathrm{n}+1}$ compared to that of tool No. $\mathrm{T}_{\mathrm{n}} . F_{\mathrm{n}}$ represents the thrust force value of tool No.T $T_{n} . F_{n+1}$ represents the thrust force value of tool No. $T_{n+1}, n=2,3,4$, $5,6,7$.

In this paper, the thrust forces of common twist drill and plane rake faced twist drill were analyzed when their reference rake angle at the outer corner of lips was $30^{\circ}$. It could be seen from Figure 8 that the plane rake faced twist drill had a smaller thrust force than the common twist drill, and the thrust force reduced by $34.3 \%$. It could be seen from Figure 9 that the plane rake faced twist drill had smaller push down delamination factor than the common twist drill with the same reference rake angle of the outer corner of lips. The main reason for the smaller 
push down delamination factor of plane rake faced twist drill was that its reduction of thrust force caused the decline of pushing effect. In addition, the cutting performance of main cutting edge was improved, which led to less drilling damage. It showed that plane rake faced twist drill had the characteristic of low drilling damage.

It could be seen from Fig. 8 that as the reference rake angle increased from $26^{\circ}$ to $50^{\circ}$, the thrust force decreased from $115.53 \mathrm{~N}$ to $55.62 \mathrm{~N}$. The decreasing amplitude of thrust force was $51.8 \%$. It showed that the reference rake angle of plane rake faced twist drill affected thrust force significantly.

The decreasing amplitudes of thrust force about the plane rake face twist drills with different reference rake angle were calculated. It was found that the decreasing amplitude of thrust force gradually decreased with the increase of reference rake. It could be seen from Figure 8 that as the reference rake angle increasing, the thrust force changed relatively smooth and the decreasing amplitude of thrust force reduces from $25 \%$ to $1 \%$. It showed that the reduction of thrust force was more limited as the reference rake angle increased to a certain value. As shown in Figure 9, as the reference rake angle increasing, the push down delamination factor decreased significantly when the reference rake angle was not more than $46^{\circ}$. A small push down delamination factor was obtained when the reference rake angle was $46^{\circ}$. When the reference rake angle was $50^{\circ}$, the reduction of push down delamination would be limited. In addition to, the plane rake faced twist drill with too large reference rake angle always has a risk of tool wear. It means that it is not necessary to blindly select tools with large reference rake angle in order to get small delamination damage.

4.2. Comparison of damage between common twist drill and plane rake faced twist drill

In order to describe the damage around drilling entrance and exit more accurately, the entrance and exit was divided into 4 regions, each of them was corresponding to a quarter circle. The fiber cutting angle $\theta$ is defined as the angle between cutting speed direction and the fiber orientation of unidirectional carbon fiber layer near the thin woven glass fiber layer, as shown in Fig. 10. At first, the four regions at entrance were numbered in Fig. 10(a), and the numbers of four regions at exit in Fig. 10(b) were corresponding to that in Fig. 10(a). When the fiber cutting angle is $0^{\circ}<\theta<90^{\circ}$, it is defined as along cutting region, such as regions I and III in Figure 10(a). When the fiber cutting angle is $90^{\circ}<\theta<180^{\circ}$, it is defined as against cutting region, such as regions II and IV in Figure 10(a).
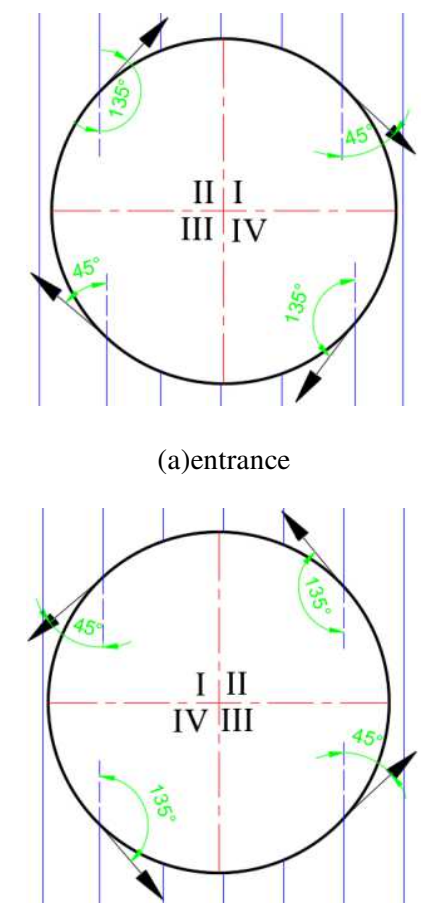

(b) exit

Fig.10. Definition of fiber cutting angle

Table 3 shows the surface morphology of drilling entrance and exit of seven plane rake 
faced twist drills and one common twist drill. The region division of drilling entrance and exit in Table 3 corresponds to that in Figure 10. The $0^{\circ}$ fiber orientation in Table 3 is defined the fiber orientation of unidirectional CFRP layer near the thin woven glass fiber layer. It could be seen from Table 3 that the burrs distribution at the drilling exit typically exhibited symmetrical regional characteristic on the hole periphery, which might be caused by the fiber-orientation symmetry relatively to the hole center [16]. The direction of burrs existing at the drilling exit was the same as the fiber orientation of unidirectional CFRP layer near the thin woven glass fiber layer, which was similar to the burrs distribution at the drilling exit when drilling unidirectional CFRP [17]. It showed that the damage of drilling exit and entrance in this paper was mainly affected by the unidirectional CFRP layer near the thin woven glass fiber layer.

The plane rake faced twist drill with $30^{\circ}$ reference rake angle was obtained by grinding the rake face of a common twist drill with $30^{\circ}$ reference rake angle at the outer corner of lips. At the outer corner of main cutting edge, the plane rake faced twist drill and common twist drill had the same reference rake angle and geometries. Along the main cutting edge of common twist drill from drill bits center to its outer corner of lip, the reference rake angle gradually increased from a negative value to a positive value, and the contribution of thrust force generated by main cutting edge to total thrust force decreased. In particular, the thrust force generated by main cutting edge close to outer corner was negative, which was upward peeling force [18]. Compared with common twist drill, plane rake faced twist drill had an larger reference rake angle at the same position of the main cutting edge. Therefore, the entire
Table.3. The hole entrance surface and hole exit surface drilled by seven plan rake face twist drills and one common twist drill

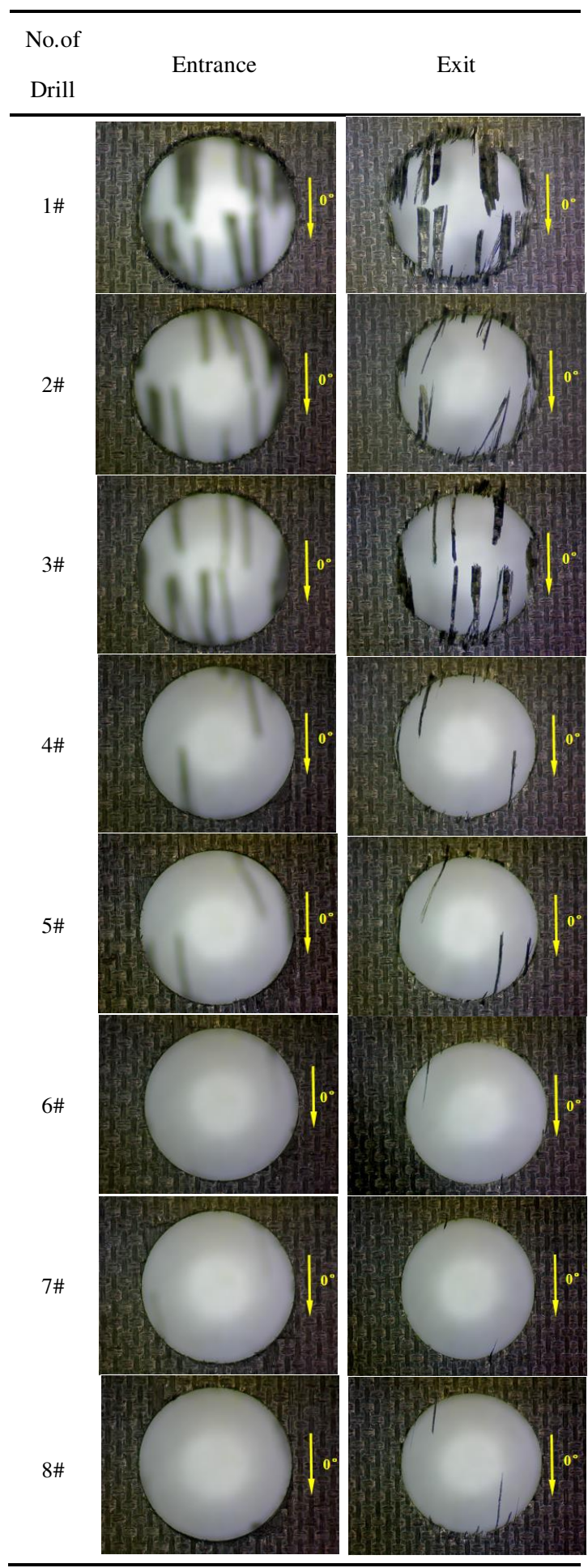

main cutting edge of plane rake faced twist drill could generate larger peeling force than that of common twist drill. As the same time, as the increase of reference rake angle, the cutting 
performance of the entire main cutting edge of plane rake faced twist drill would be improved.

As shown in Table 3 for drilling entrance, it could be seen that plane rake faced twist drill with $30^{\circ}$ reference rake angle had smaller peeling delamination than common twist drill. The plane rake faced twist drill had not only higher peeling force, but also excellent cutting behavior. The common twist drill had smaller peeling force, but it would result in worse damage at entrance than plane rake faced twist drill due to its bad cutting performance. It indicated that the peeling delamination of drilling entrance was not just affected by the peeling force of the entire main cutting edge, but by the cutting behavior of the entire main cutting edge. At the exit of drilling, it could be seen that plane rake faced twist drill had less overhanging burrs than common twist drill when the reference rake angle at the outer corner of lips was the same. In Figure 9, it further showed that plane rake faced twist drill caused less delamination damage of drilling exit than common twist drill. Therefore, it showed that when the reference rake angle at the outer corner of lips was the same, plane rake faced twist drill could obtain smaller delamination damage of drilling entrance and exit of CFRP with thin woven glass fiber layer than common twist drill .

4.3. Damage mechanism analysis of different plane rake faced twist drills

\subsubsection{Entrance damage analysis}

Figure 11 shows the micro-morphology of drilling entrance of different plane rake faced twist drills. When the reference rake angle was the same, the damage of against cutting region II was more serious than that of along cutting region III. Taking the entrance damage produced by the plane rake faced twist drill with $26^{\circ}$ reference rake angle as an example, the cavities caused by compression-induced stress in the against cutting region of entrance extended to the hole periphery longer than that caused by tensile-induced stress in along cutting region of entrance, seen Figure 11 (a) and (b). Taking the entrance damage produced by the plane rake faced twist drill with $42^{\circ}$ reference rake angle as an example, the cavities caused by compression failure in against cutting region of entrance was deeper than that in along cutting region of entrance, as shown in Figure 11(c) and (d). The study of Wang et al. [19] showed that in the along cutting region, the force component along the fiber axis created a tensile stress to make the fibers easier to break in the neighbourhood of the cutting zone, resulting in smaller surface roughness and subsurface damage. In addition, the fibers were subjected to an axial compression in the against cutting region. It couldn't provide great support when the surrounding fragile matrix cracks. Thus a machined surface normally had many protruded fibers that resulted in a greater surface roughness.

As the increases of reference rake angle of the plane rake faced twist drill, the damage in along cutting region and against cutting region of entrance generally decreased. But when the reference rake angle was larger than $42^{\circ}$, the damage reduction of drilling entrance was not significant. As shown in Figures 11(b) and 11(d), with the increase of reference rake angle, the area of cavities caused by compression-induced failure in along cutting region gradually decreased. However, Figure 11(e) and (f) showed that when the reference rake angle was $50^{\circ}$, there was damage in both along cutting region and against cutting region of entrance. The damage in against cutting region of the 
Fig.11.Micro morphology at the entrance surface of drilling hole.

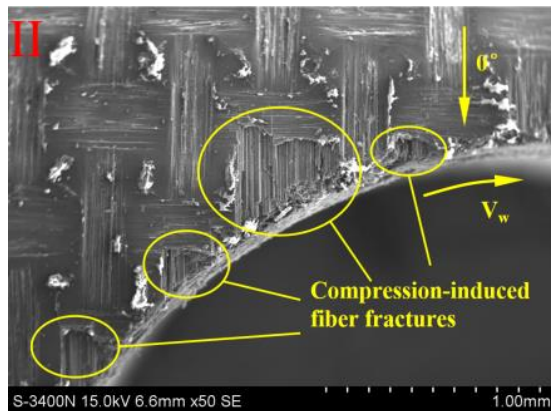

(a) $26^{\circ}$ against fiber cutting region

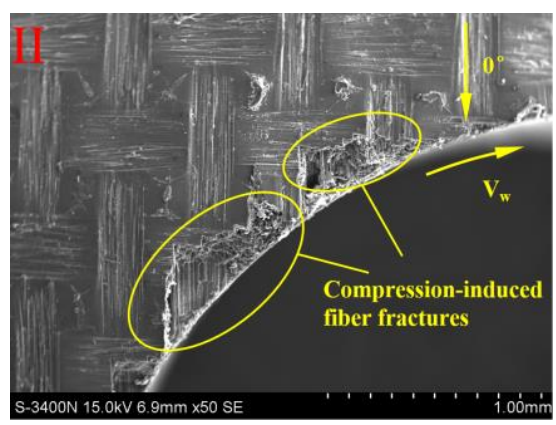

(c) $42^{\circ}$ against fiber cutting region

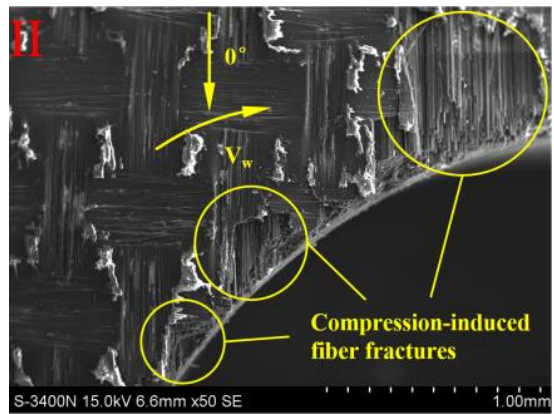

(e) $50^{\circ}$ against fiber cutting region

As the reference rake angle of the plane rake faced twist drill increased, the upward peeling force generated at each point along the main cutting edge increased. At the same time, the cutting performance of drill was gradually improved with the increase of reference rake angle [20]. Therefore, the drilled surface quality at entrance about plane rake faced twist drill was influenced by the combination of cutting behavior and peeling force. When the reference rake angle was smaller than $42^{\circ}$, with the increase of the reference rake angle of the plane

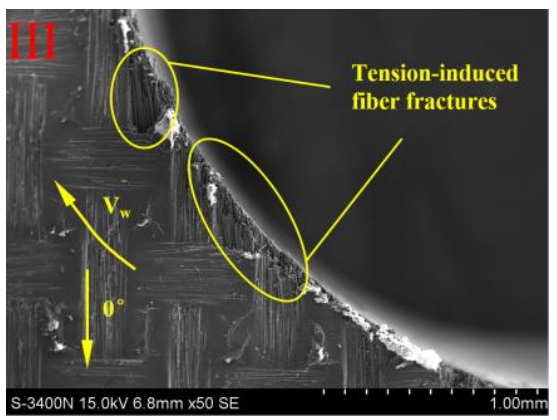

(b) $26^{\circ}$ along fiber cutting region

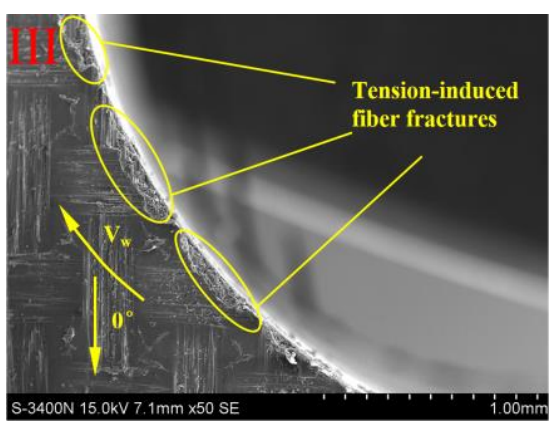

(d) $42^{\circ}$ along fiber cutting region

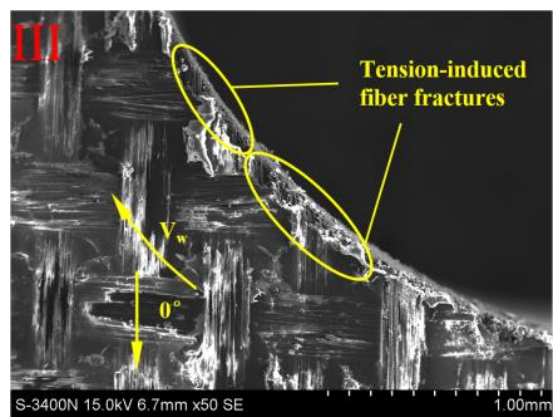

(f) $50^{\circ}$ along fiber cutting region

rake faced twist drill, the damage at entrance decreased, the peeling delamination didn't increase as the increase of peeling force. It proved that when the reference rake angle was smaller than $42^{\circ}$, the surface quality at entrance was mainly affected by cutting performance of plane rake faced twist drill and less affected by peeling force. When the reference rake angle was larger than $42^{\circ}$, the damage of drilling entrance increased with the increase of reference rake angle. This phenomenon indicated that even though the cutting behavior of plane rake faced 
twist drill was improved, it couldn't obtain better surface quality at entrance. On the contrary, the surface quality at entrance reduced owing to larger peeling force. Therefore, when the reference rake angles was larger than $42^{\circ}$, the surface quality at entrance was significantly affected by peeling force. In order to obtain best surface quality at entrance, it was recommended to use a plane rake faced twist drill with a reference rake angle of $42^{\circ}$.

\subsubsection{Exit damage analysis}

As shown in Table 3, the overhanging burrs were existing in all the along cutting regions of drilling exits. However, the overhanging burrs only existed in the against cutting region of drilling exit when the reference rake angle of the plane rake faced twist drill were $26^{\circ}$ and $30^{\circ}$. With the increase of the reference rake angle of the plane rake faced twist drill, the burrs firstly decreased in the along cutting region of drilling exit. When the reference rake angle of the plane rake faced twist drill was larger than $46^{\circ}$, the burrs increased in the along cutting region of drilling exit. The burrs also firstly decreased in the against cutting region of drilling exit with the increase of reference rake angle of the plane rake faced twist drill. When the reference rake angle of the plane rake faced twist drill increased to $38^{\circ}$, there was no burr damage in the against cutting region of drilling exit. When the reference rake angle of was $50^{\circ}$, the tiny burrs appeared.

The existence of burrs was associated with axial pushing effect and circumferential cutting behavior at the drilling exit. Hintze et al. [21] pointed out that due to fibers or fiber bundles could repeatedly avoid the tool during its feed motion, thus the fibers or fiber bundles were bent either in the laminate plane or perpendicular to it. The fibers would not be broken if the bending did not reach its transverse fracture strength. Jia et al. [22] believed that in terms of basic mechanical properties, the longitudinal tensile strength, transverse shear strength and transverse compression strength of the fiber are always much higher than the bonding strength between the fiber and matrix. Therefore, in the along cutting region of drilling exit, the fiber/matrix interface debonding damage appeared under the pushing behavior of thrust force, resulting in the fibers of unidirectional CFRP layer near the thin woven glass fiber layer became too soft. When the lowermost carbon fibers were cut by the main cutting edge, it couldn't provide compressive shear stress, so the lowermost carbon fibers would suffer from large axial bending deformation under the continuous downward feed of the plane rake faced twist drill. It would reduce the transverse cutting stress of fibers in the contact area, which would lead to less fibers break. Therefore, the existence of burrs was greatly influenced by axial pushing in the along cutting region of drilling exit.

$\mathrm{Xu}$ et al. [23] showed that the burr defect occurred in the against cutting region of drilling exit. It might attribute to that the bending-dominated failure mode governed the chip separation in this region. In the against cutting region of drilling exit, the bending-dominated chip separation mode made the circumferential bending deformation of the lowermost carbon fiber more complex than that in the along cutting region. At the same time, the axial pushing made carbon fibers lose the support of matrix, causing the axial bending of lowermost carbon fibers. Under the combined action of axial bending and circumferential bending, the fibers would appear more serious bending deformation. In the against cutting region of drilling exit, the stress concentration 
mainly appeared at the maximum curvature point of fiber bending deformation below the cutting edge. When the bending stress of fibers reached the bending strength, fibers would happen bending fracture. When the bending stress of fibers didn't reached the bending strength, they were pressed below the clearance face of the drill until the drilling process was completed. It resulted in the fibers were not separated from workpiece and finally burrs were formed.

The axial pushing generated by drill existed along the whole hole circumference at the drilling exit. According to the research of Bonnet et al. [24], it showed that the drilling exit delamination damage was mainly concentrated in the along cutting region and the position near $0^{\circ} / 180^{\circ}$ fiber cutting angle. The local thrust force in the along cutting region of drilling exit was larger than that in the against cutting region of drilling exit. It further made the axial pushing effect in the along cutting region of exit was larger compared to that in the against cutting region of drilling exit, which resulted in more serious burrs damage. Therefore, when the reference rake angle of plane rake faced twist drill were the same, the burrs distribution in the along cutting region of drilling exit was much more than that in the against cutting region of drilling exit.

As shown in Figure 12, the against cutting region was divided into two situations, when the fiber cutting angle $\theta>90^{\circ}+\gamma_{n}$, the rake face contacted with fibers firstly, then the fibers were bent and deformed through the action of rake face. Its crack extension was more complicated than that in the along cutting region of exit. When the drill continues to cut along the hole circumference, the pressure from rake face increased and then the tensile failure of fibers and compressive shear failure occurred. This situation was mainly based on the bending fracture of fibers. When the fiber cutting angle $\theta<90^{\circ}+\gamma_{n}$, the cutting edge firstly contacted with fiber, and the compressive and shear extrusion fracture was generated in vertical fiber direction. The fibers were sheared off by cutting edge in local contact area and then the fractured fibers were pushed by the rake face along the circumferential cutting direction. Next, it moved outward along the fiber direction and then was separated from the material to form chips. This situation was mainly dominated by the compression shear fracture of fibers.

From Equation (3), it could be seen that the reference rake angle of plane rake faced twist drill was positively correlated with the normal rake angle. In the along cutting region, due to the fiber cutting angles $\theta$ always satisfied $\theta<90^{\circ}+\gamma_{n}$, so the increase of the reference rake angle didn't change the shear-dominated fiber fracture mode. It was further showed that the reduction of damage in the along cutting region of drilling exit was mainly influenced by the reduction of thrust force, but not by the fiber fracture mode.

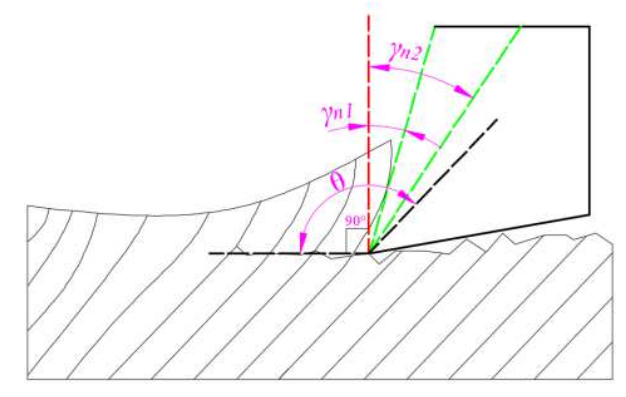

Fig.12 Diagrammatic sketch of cutting with different rake angles

In the against cutting region of drilling exit, when the fiber cutting angle remained unchanged, the pushing along the circumferential cutting direction was decreased 
with the increase of normal rake angle $\gamma_{\mathrm{n}}$, as shown in Figure 12. Before the bending stress of fibers reached bending strength, the cutting edge contacted with the fibers in local contact area to generate compressive shear load, which caused the shear failure of fibers. Therefore, the shearing effect of drill was enhanced and the bending effect was weakened when $\theta<90^{\circ}+\gamma_{n}$ in the against cutting region. At the same time, in the against cutting region of drilling exit, the increase of reference rake angle would extend the range of $\theta<90^{\circ}+\gamma_{\mathrm{n}}$. As shown in Table 3 , there are burrs when $\theta>90^{\circ}+\gamma_{n}$ and $\theta<90^{\circ}+\gamma_{n}$ in the against cutting region of drilling exit. As the increase of the reference rake angle of plane rake faced twist drill, it didn't affect the generation of burrs when the fiber cutting region change from $\theta>90^{\circ}+\gamma_{n}$ to $\theta<90^{\circ}+\gamma_{n}$, so the change of fiber fracture mode does not affect the generation of burrs. In addition, the thrust force gradually decreased with the increase of the reference rake angle of plane rake faced twist drill in the Figure 8. Therefore, as the increase of the reference rake angle of plane rake faced twist drill, the reduction of damage in the against cutting region of drilling exit was mainly influenced by the thrust force and the cutting performance. As shown in Figs. 13(a) and 13(b), at the position with the same fiber cutting angle in against cutting region II of drilling exit, the plane rake faced twist drill with $46^{\circ}$ reference rake angle generated better drilling quality compared to the plane rake faced twist drill with $38^{\circ}$ reference rake angle.

The Table 3 showed that the improvement of drilling quality was not significant when the reference rake angle of plane rake faced twist drill was larger than $46^{\circ}$, which was due to serious tool wear of the plane rake faced twist drill with large reference rake angle. The plane rake faced twist drill with $50^{\circ}$ reference rake angle could achieve the fiber shearing and chip

Fig.13 Micro morphology at the exit surface of tool drilling hole.

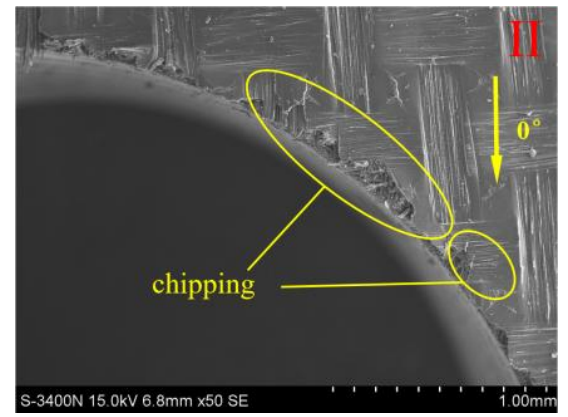

(a) $38^{\circ}$ against fiber cutting region

Fig.14.Micro morphology tipping of too

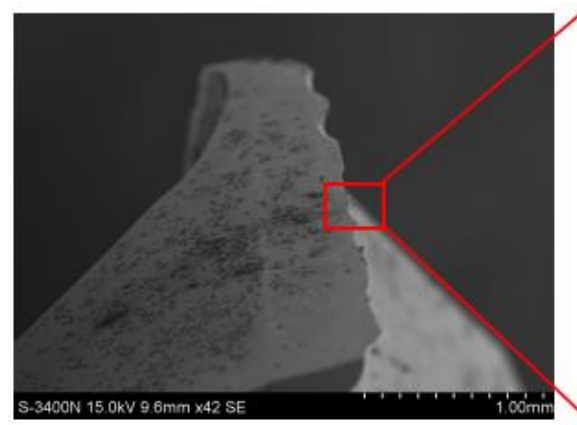

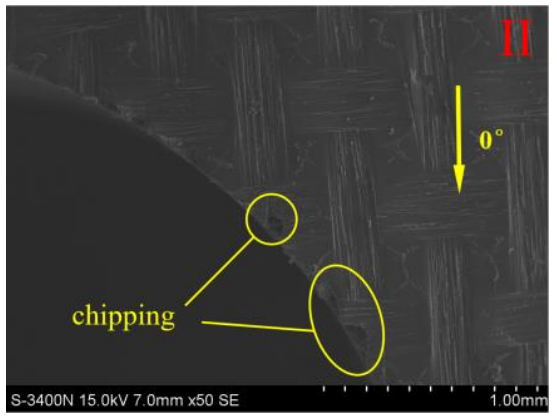

(b) $46^{\circ}$ against fiber cutting region

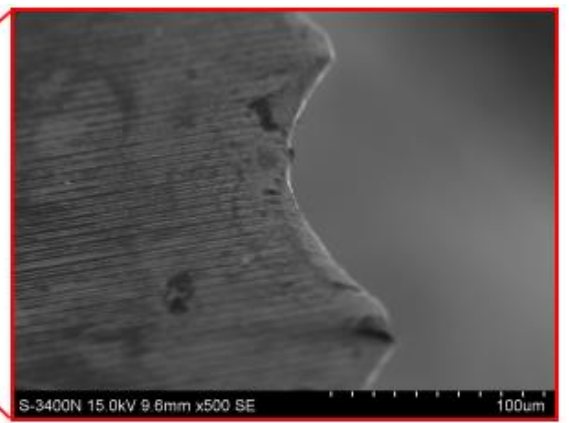


disposal easily, but there was serious tool wear and edge chipping phenomenon in Figure 14. The serious tool wear would increase the main cutting edge radius of the plane rake faced twist drill. With the increase of the cutting edge radius of the plane rake faced twist drill, the fiber fracture mode for the fiber cutting angle $\theta<90^{\circ}+\gamma_{n}$ would change from shearing-dominated fiber fracture mode to the bending-dominated fiber fracture mode, leading to fiber deflect without being broken [25]. So, in order to obtain low damage at exit, it was recommended to use a plane rake faced twist drill with a reference rake angle of $46^{\circ}$.

\subsection{The effect of thin woven surface on damage}

The CFRP laminate surface was thin woven glass fibers layer. As shown in Figure 4, the orientation of glass fibers in woven surface were $0^{\circ} / 90^{\circ}$. Rahme et al. [15] proposed that added a woven glass fiber layer at the bottom of workpiece increased the critical thrust force and then decreased delamination.

Turki et al. [26] believed that the initial damage of the drilling entrance was mainly the fiber/matrix interface fracture and matrix fracture, resulting in the propagation of cracks over a larger distance. When the fibers were not cut, burrs and delamination were formed. In this paper, there was no burr damage at the drilling entrance, but just slight delamination was generated. It was attributed to the delamination inhibition given by thin woven glass fiber layer. In the against cutting region of drilling entrance, the $0^{\circ}$ oriented carbon fibers on uppermost layer were subjected to upward force including peeling force and bending-induced stresses[27,28]. As showed in the rectangular region of Figure $15(\mathrm{a})$, the $90^{\circ}$ oriented glass fibers in woven layer suppressed the bending-induced force and peeling force of $0^{\circ}$ oriented carbon fibers on the uppermost layer.

Fig. 15 Micro morphology at the entrance surface of $30^{\circ}$ tool drilling hole.

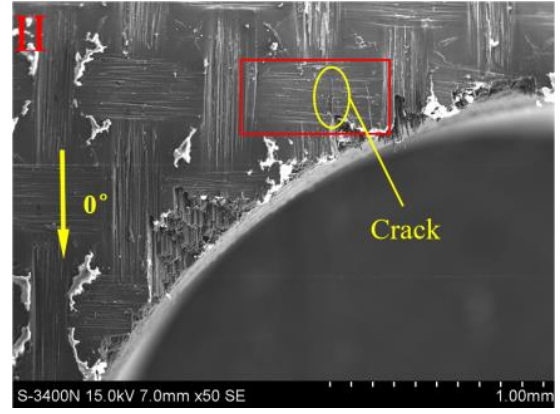

(a) $30^{\circ}$ against fiber cutting region

Fig.16 Micro morphology at the exit surface of tool drilling hole

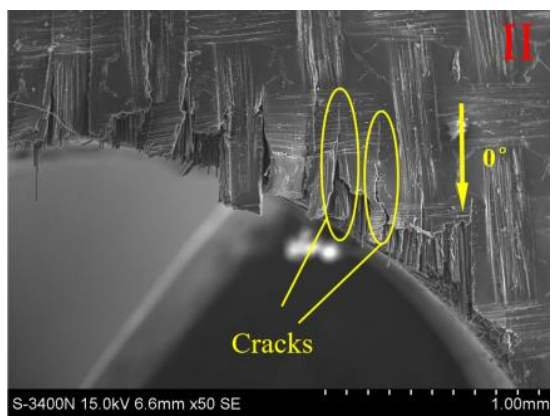

(a) $30^{\circ}$ against fiber cutting region

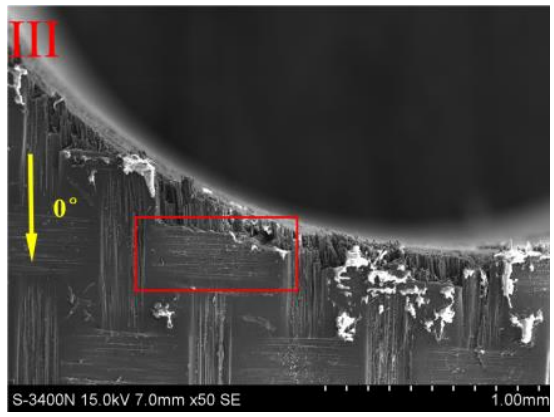

(b) $30^{\circ}$ along fiber cutting region

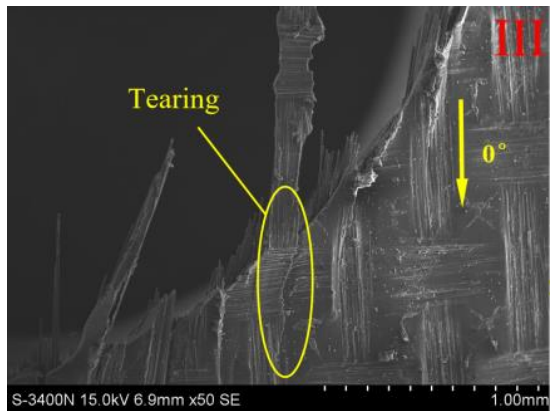

(b) $30^{\circ}$ along fiber cutting region 
When the stress generated by resultant force of bending-induced force and peeling force exceeded the shear strength of $90^{\circ}$ oriented glass fibers, cracks continued to extend through the $90^{\circ}$ oriented glass fibers. As shown in Figure 15(b), in the along cutting region of drilling entrance, the $0^{\circ}$ oriented carbon fiber on uppermost layer was only subjected to the peeling force. Therefore, in the along cutting region of drilling entrance, the shear strength of $90^{\circ}$ oriented glass fibers in woven layer was sufficient to only resist the upward stress generated by the peeling force of $0^{\circ}$ oriented carbon fiber on the uppermost layer, which inhibited the peeling delamination. The thin woven glass fiber layer on the surface of CFRP laminate had the inhibition effect on peeling delamination at drilling entrance.

The thin woven glass fibers layer also had a certain degree of delamination suppression effect at the drilling exit. Figures 16(a) and 16(b) showed the drilling exit morphology about the plane rake faced twist drill with $30^{\circ}$ reference rake angle, which was corresponding to that in the entrance regions II and III shown in Figure 15. As shown in Figure 16(a), the propagating distance of cracks along the lowermost layer of $0^{\circ}$ carbon fiber orientation was longer than the cracks along the uppermost layer of $0^{\circ}$ carbon fiber orientation in Figure 15(a). Like the entrance, bending-induced stress also existed in the against cutting region of drilling exit. In addition, there were large axial pushing at the drilling exit. In the against cutting region of drilling exit, the $90^{\circ}$ oriented glass fiber was difficult to inhibit the propagation of cracks along the lowermost layer of $0^{\circ}$ carbon fiber orientation due to the existence of bending-induced force and thrust force. Compared to the along cutting region of drilling entrance, the thrust force in the along cutting region of drilling exit was much bigger than the peeling force. As shown in Figure 15(b) and 16(b), the cracks propagating distance of the drilling exit was longer than that of the drilling entrance. Therefore, the glass fiber in thin woven layer only had a certain inhibition effect on push down delamination at the drilling exit.

\section{Conclusions}

In this paper, one common twist drill and seven plane rake faced twist drills with different reference rake angle were used to drill CFRP with thin woven glass fiber layer. The characteristic of low drilling damage with plane rake faced twist drill compared with the common twist drill was studied. In addition, the effect of plane rake faced twist drills with different reference rake angle and thin woven glass fiber surface on the drilling quality of drilling entrance and exit of CFRP laminate with thin woven glass fiber surface layer were also studied. It could draw some conclusions.

(1) Compared to the common twist drill, the plane rake faced twist drill could generate smaller thrust force. Due to the constant value of the reference rake angle of plane rake faced twist drill, the increase of thrust force was more stable when the main cutting edge was gradually drilled into the drilling entrance. The thrust force decreased with the increase of reference rake angles, but when the reference rake angles increased from $46^{\circ}$ to $50^{\circ}$, the decreasing amplitude of thrust force was only $1 \%$. Therefore, the reduction of thrust force was limited when the reference rake angle of plane rake faced twist drill increased to a larger value. (2) The drilling entrance damage produced by plane rake faced twist drill and common twist drill at the same reference rake angle at the outer 
corner of lips were compared. It was revealed that the drilling entrance damage was not just influenced by the peeling force of the entire cutting edge, also by the cutting behavior of the entire cutting edge. The drilling entrance damage produced by plane rake faced twist drill was less than that of the common twist drill. Compared the push down delamination factor of drilling exit, it showed that the push down delamination factor generated by plane rake faced twist drill was smaller than that generated by the common twist drill. Therefore, plane rake faced twist drill had the characteristic of low drilling damage compared to common twist drill.

(3) When the plane rake faced twist drill was used to drill CFRP with thin woven glass fiber layer, the drilling surface quality at the entrance was influenced by the combination of cutting behavior and peeling force. When the reference rake angle of plane rake faced twist drill was $42^{\circ}$, the best surface quality of drilling entrance was achieved. The existence of burrs in the along cutting regions and against cutting region at drilling exit was the result of combined action of axial pushing behavior and circumferential cutting behavior, and the best drilling quality at exit was achieved with the $46^{\circ}$ reference rake angle. As drilling damage at exit had a greater impact on the drilling quality of holes than the drilling damage at entrance. So, when the plane rake faced twist drill was used to drill CFRP laminates with thin woven glass fiber surface, a plane rake faced twist drill with $46^{\circ}$ reference rake angle should be recommended.

(4) The addition of thin woven glass fiber layer on the CFRP laminate surface could inhibit the peeling delamination well at drilling entrance, and it could also have a certain inhibiting effect on push down delamination at drilling exit.
Acknowledgements The authors would like to thank the anonymous reviewers for their valuable comments and suggestions to improve the quality and readability of the paper

Author contribution Methodology: Liping Liu and Bo Lian; experimental work: Bo Lian, Kehao Duan, Changgeng Zhou, Xueming Zhu, Pingfeng Xia; data analysis: Liping Liu, Bo Lian, and Kehao Duan; writing the first draft: Bo Lian; writing, review and editing: Liping Liu, Bo Lian; funding acquisition: Liping Liu. All authors have read and agreed to the published version of the manuscript.

Funding This project is supported by Basic Scientific Research Foundation of Central University (No. $3122019081)$.

Availability of data and materials All data generated or analyzed during this study are included in this article.

\section{Declarations}

Ethics approval Not applicable.

Consent to participate Not applicable.

Consent for publication Not applicable.

Competing interests The authors declare no competing interests.

\section{References}

1. Soutis C . Fibre reinforced composites in aircraft construction, Progress in Aerospace Sciences. 41 (2) (2005) 143-151

2. Geng, D. , et al.,Delamination formation and suppression during rotary ultrasonic elliptical machining of CFRP, Composites. 183.Feb.15 (2020) 107698.1-107698.12

3. Vigneshwaran S, Uthayakumar M, Arumugaprabu V. Review on machinability of fiber reinforced polymers: a drilling approach, Silicon. 10 (5) (2018) 2295-2305 
4. kshay H , Dilpreet S, Sagar K, et al. Machining damage in FRPs: Laser versus conventional drilling, Composites Part A Applied Science and Manufacturing. 82 (2015) 42-52

5. Lazar M B , Xirouchakis P . Experimental analysis of drilling fiber reinforced composites, International Journal of Machine Tools \& Manufacture. 51 (12) (2011) 937-946

6. Abdullah A B , Zain M , Abdullah M S, et al. Delamination measurement of a laminates composite panel due to hole punching based on the focus variation technique, Proceeding of the International Conference of Global Network for Innovative Technology. AIP Publishing LLC, 2017

7. Su F, Zheng L, Sun F, Wang Z, Deng Z, Qiu X. Novel drill bit based on the stepcontrol scheme for reducing the CFRP delamination, J Mater Process Technol. 262 (2018) 157-167

8. Xu J, An Q, Cai X, Chen M. Drilling machinability evaluation on new developed high-strength T800S/250F CFRP laminates, International Journal of Precision Engineering\&Manufacturing. 14 (10) (2013) 1687-1696

9. Qiu X, Li P, Niu Q, Chen A, Ouyang P, Li C, et al. Influence of machining parameters and tool structure on cutting force and hole wall damage in drilling CFRP with stepped drills, International Journal of Precision Engineering\&Manufacturing. 97 (1) (2018) 857-865

10. Wang X, Shen X, Zeng C, Sun F. Combined influences of tool shape and as-deposited diamond film on cutting performance of drills for CFRP machining, Surface \& Coatings Technology. 347 (2018) 1-40

11. Geier N, Davim J P, Szalay T . Advanced cutting tools and technologies for drilling carbon fibre reinforced polymer (CFRP) composites: A review, Composites Part A Applied Science and Manufacturing. 125 (2019) 105552.1-105552.15

12. Drilling with flat rake face and conventional twist drills-I. Theoretical investigation, International Journal of Machine Tool Design and Research. 12 (1) (1972) 17-35

13. Lo S Y, Lode U, Armarego E . Experiments with controlled-contact tools, International Journal of Machine Tool Design \& Research. 6 (3) (1966) 115-127

14. Wang J , Zhang Q . A study of high-performance plane rake faced twist drills.: Part I: Geometrical analysis and experimental investigation, International Journal of Machine Tools \& Manufacture. 48 (11) (2008) 1276-1285

15. P. Rahme, P. Moussa, F. Lachaud, Y. Landon,Effect of adding a woven glass ply at the exit of the hole of CFRP laminates on delamination during drilling, Composites Part A: Applied Science and Manufacturing. 129 (2020) 105731.6-105731.7

16. Jinyang, $\mathrm{Xu}$, Qinglong, et al. An experimental investigation on cutting-induced damage when drilling high-strength T800S/250F carbon fiber-reinforced polymer, Proceedings of the Institution of Mechanical Engineers Part B Journal of Engineering Manufacture. (2015) 5-6

17. Su F, Deng Z, Qiu X, et al. Morphological characteristics and formation mechanisms of the UD-CFRP drill exit-damages, International Journal of Advanced Manufacturing Technology. 107 (19) (2020) 2372-2373

18. Armanios E A, Bucinell R B , Wilson D W , et al. Drilling Damage of GFRP and Residual Mechanical Behavior-Part I: Drilling Damage Generation, Journal of Composites Technology and Research. 23 (2) (2001) 127-128

19. Wang X M , Zhang L C . An experimental investigation into the orthogonal cutting of unidirectional fibre reinforced plastics, International Journal of Machine Tools \& Manufacture. 43 (10) (2003) 1015-1022

20. Ahmad J. Machining of polymer composites. US: Springer; (2009) 63-226

21. Hintze W , Hartmann D . Modeling of Delamination During Milling of Unidirectional CFRP, Procedia CIRP. 8 (2013) 444-449

22. Jia Z, Fu R, Niu B , et al. Novel drill structure for damage reduction in drilling CFRP composites, International Journal of Machine Tools \& Manufacture. 110 (2016) 58-59

23. Jinyang $\mathrm{Xu}$ a b, Qinglong An $\mathrm{b}$, Ming Chen $\mathrm{b}$. A 
comparative evaluation of polycrystalline diamond drills in drilling high-strength T800S/250F CFRP -

ScienceDirect, Composite Structures. 117 (1) (2014) 71-82

24. Poulachon, Gerard, Bonnet, et al. CFRP drilling: Fundamental study of local feed force and consequences on hole exit damage, International Journal of Machine Tools \& Manufacture Design Research \& Application. 94 (2015) (2015) 57-64

25. Wang F J, Yin J W, Ma J W, et al. Effects of cutting edge radius and fiber cutting angle on the cutting-induced surface damage in machining of unidirectional CFRP composite laminates, International Journal of Advanced Manufacturing Technology. 91 (2017) 3113-3114

26. Yosra, Turki, Malek, et al. Experimental investigation of drilling damage and stitching effects on the mechanical behavior of carbon/epoxy composites, International Journal of Machine Tools and Manufacture. S0890-6955(14)00090-X (2014)

27. Cheng H, Gao J, Kafka O L, et al. A micro-scale cutting model for UD CFRP composites with thermo-mechanical coupling, Composites Science and Technology. S0266-3538(17)31276-9 (2017)

28. DeFu Liu a, YongJun Tang b c, W.L. Cong c. A review of mechanical drilling for composite laminates, Composite Structures. 94 (4) (2012) $1265-1279$ 
Figures

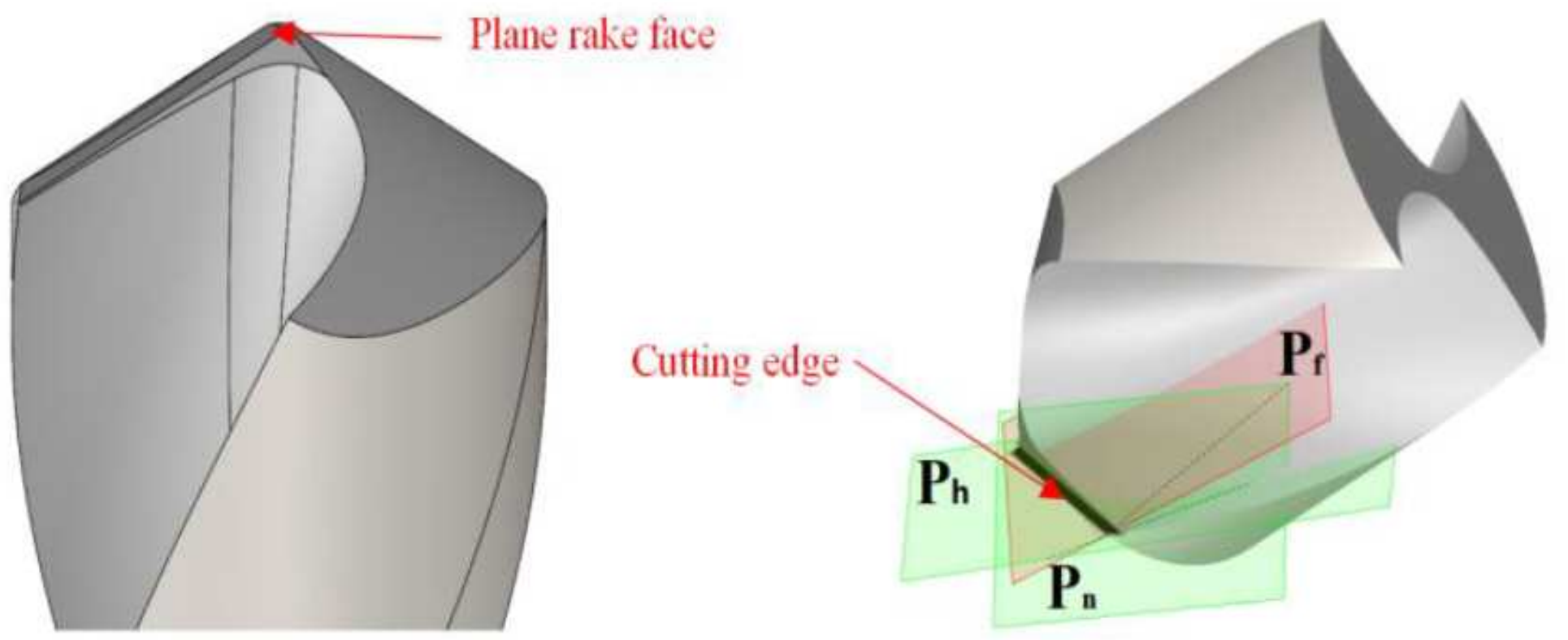

Figure 1

Geometry of a plane rake faced drill. 


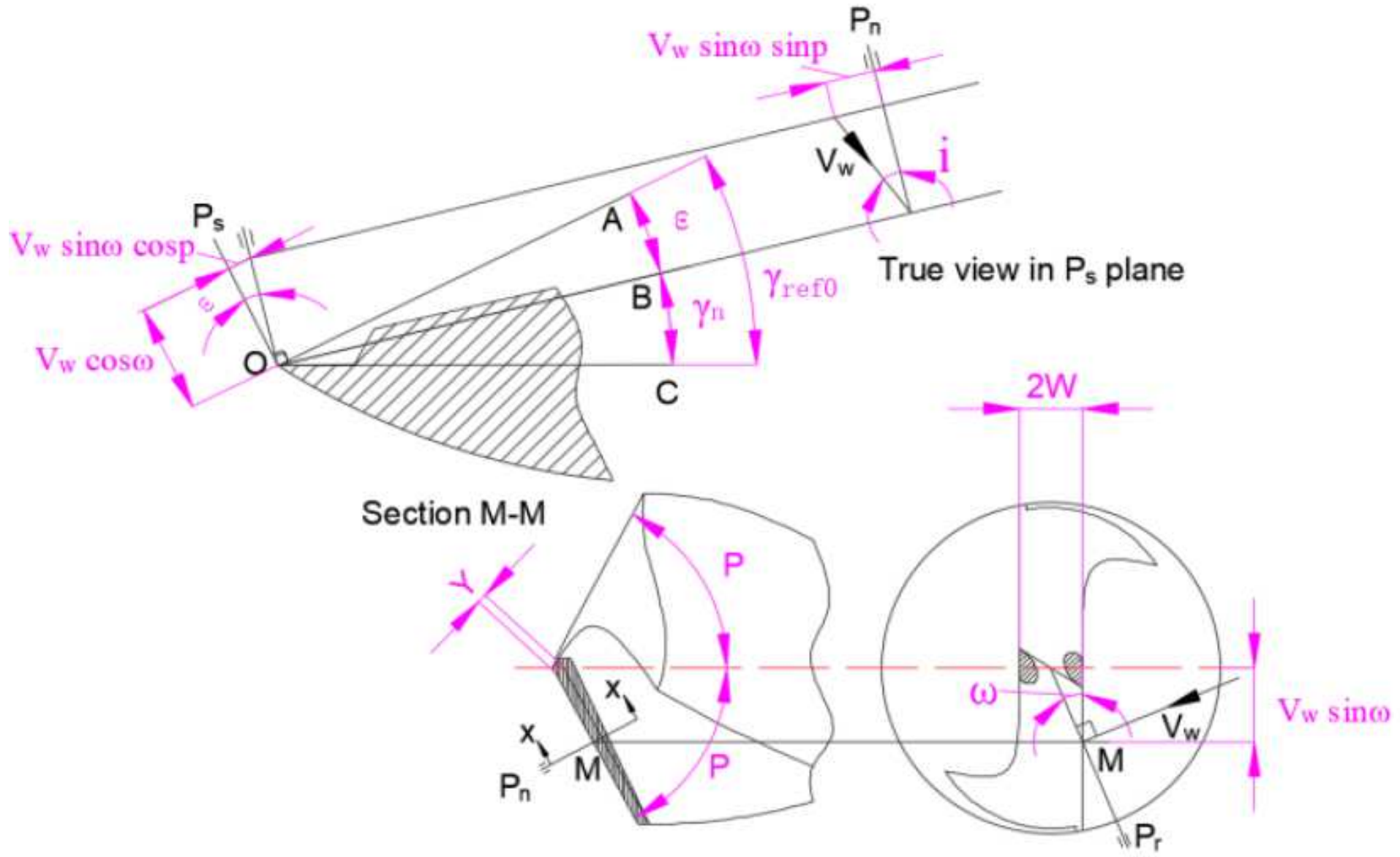

Figure 2

Geometrical relationship between various "fundamental" and specified drill angles at the lips of a plane rake faced drill 


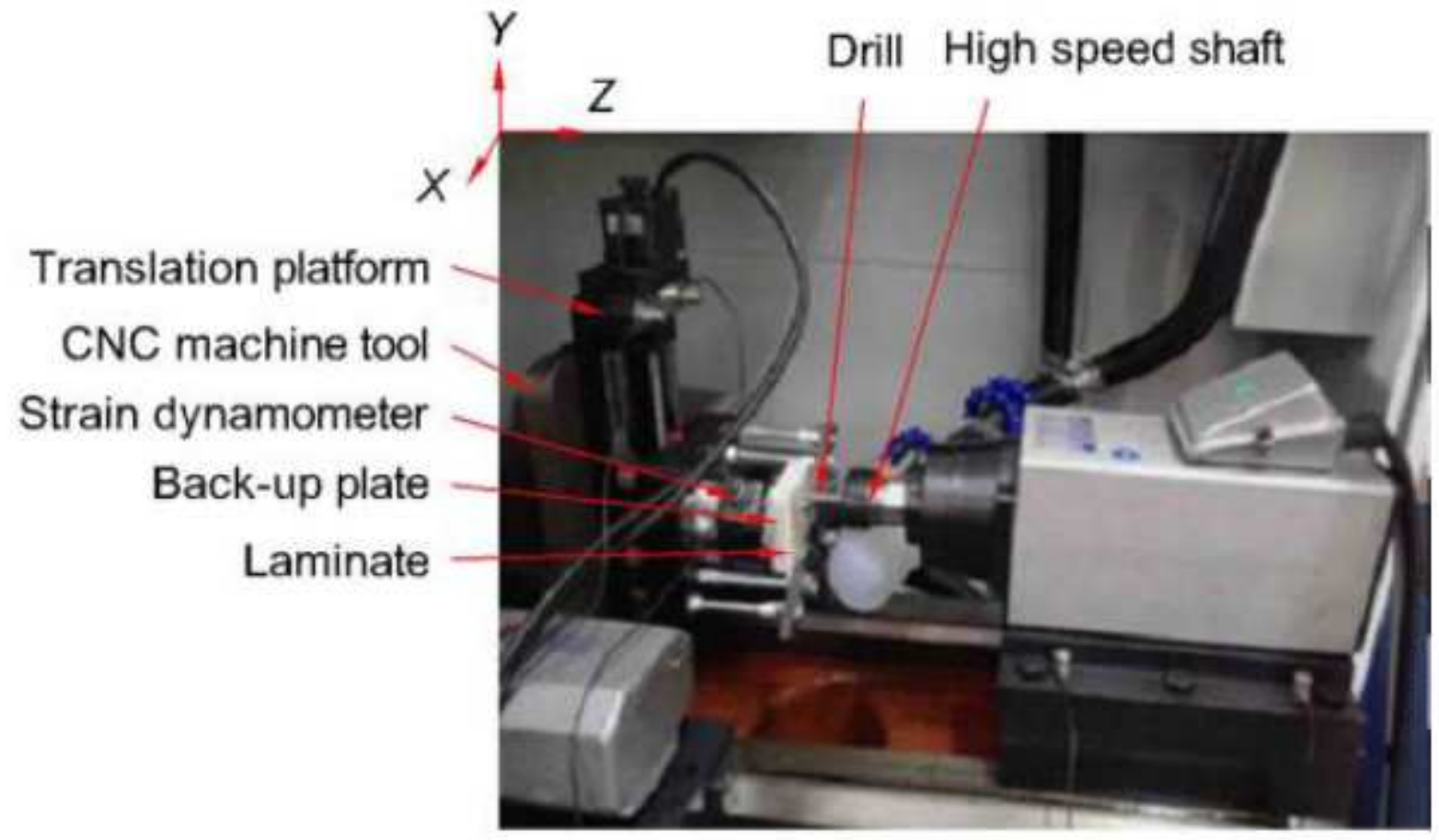

Figure 3

Experiment platform.

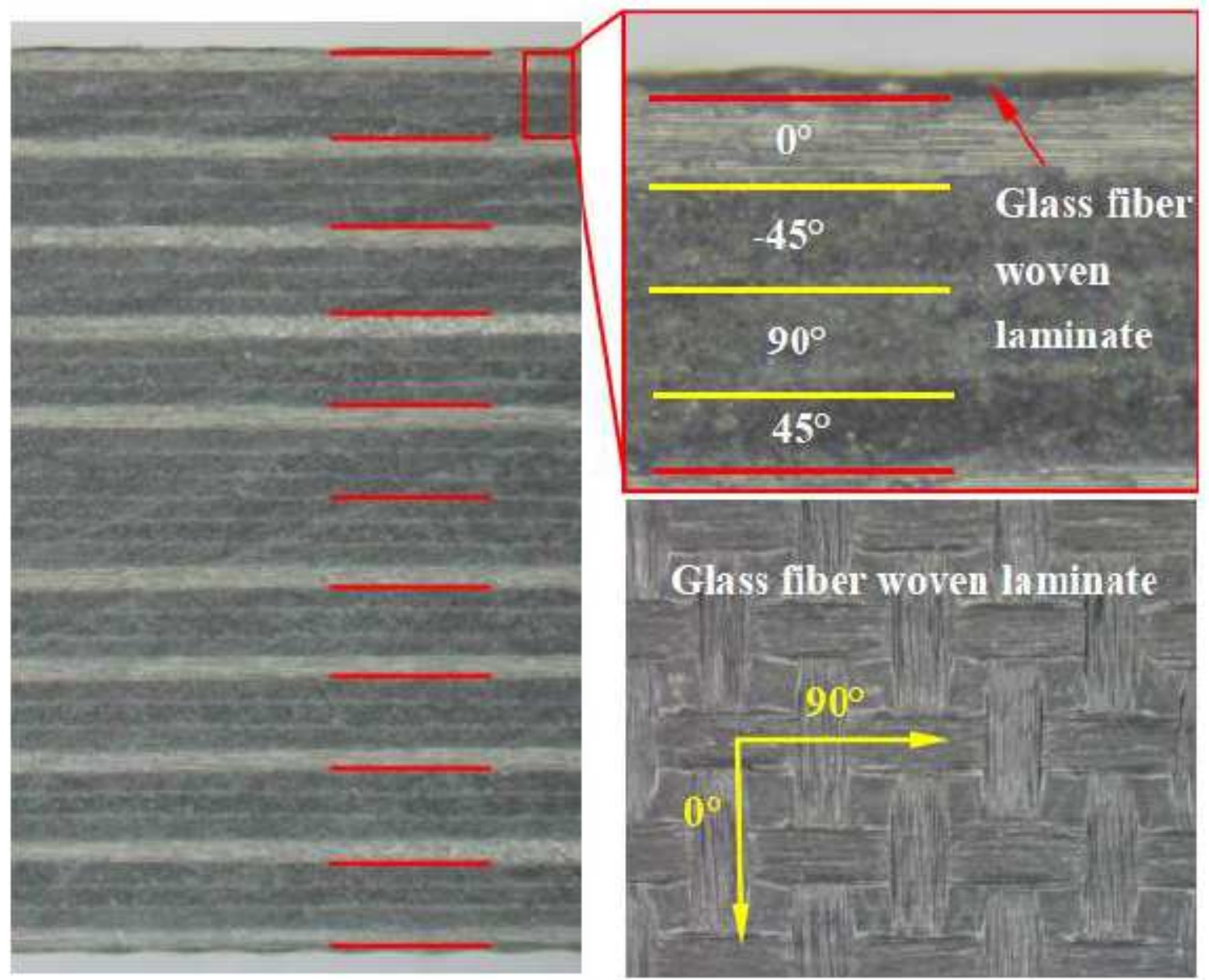

Figure 4 
Layer morphology.

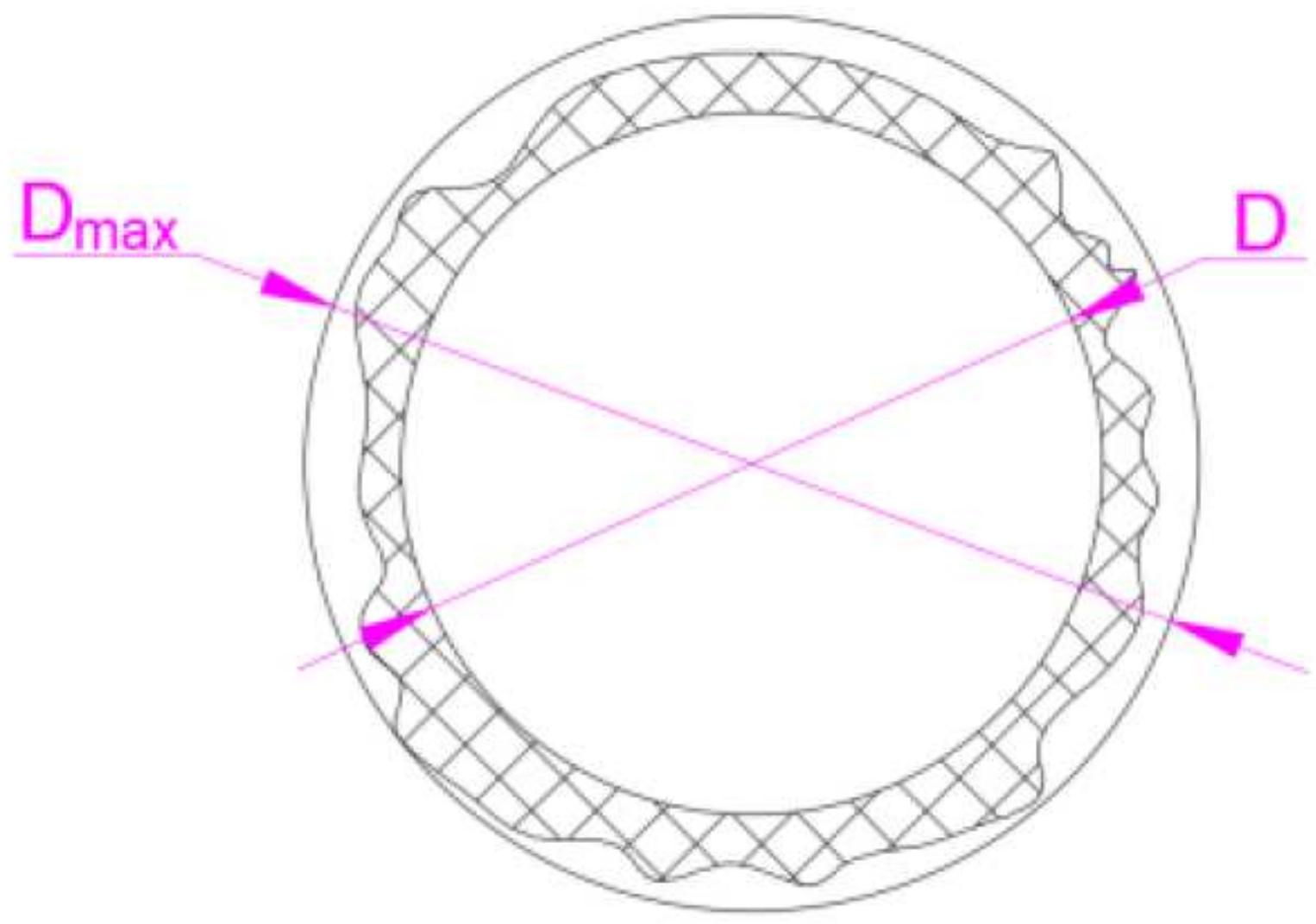

Figure 5

Delamination damage factor. 


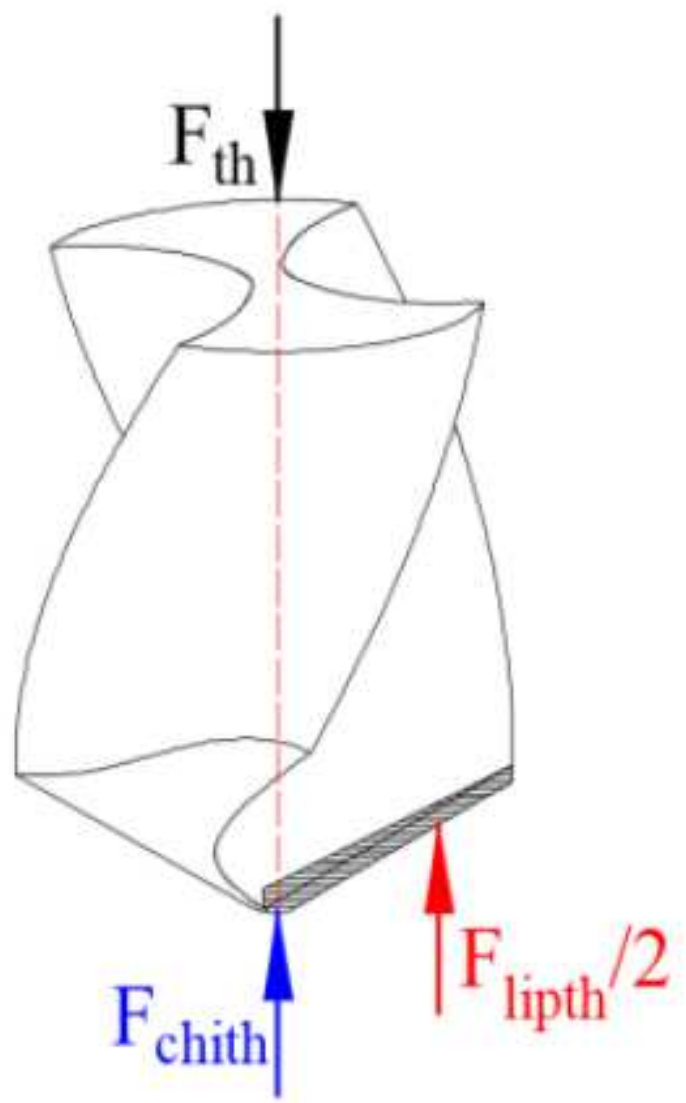

Figure 6

Thrust force distribution of plane rake faced twist drill.
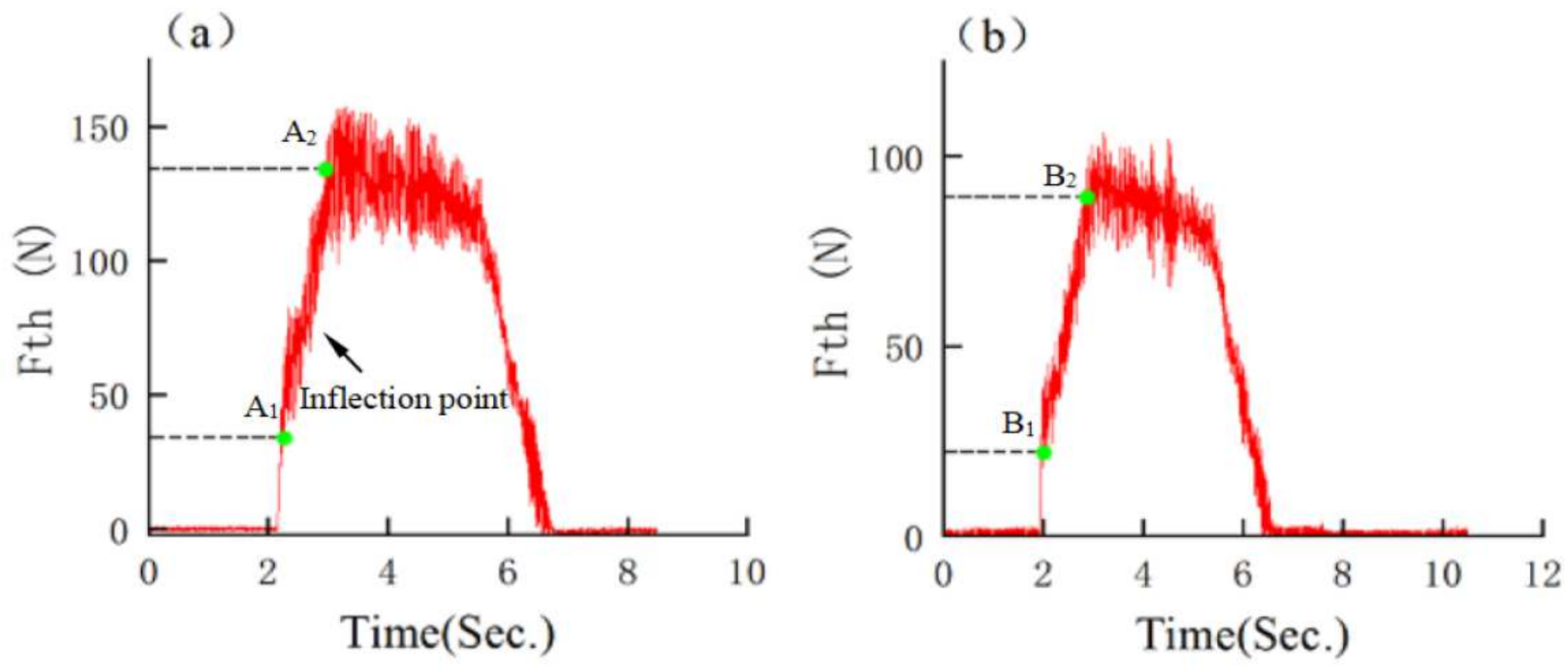

Figure 7

Typical thrust forces signals recorded during drilling. (a) common twist drill with $30^{\circ} \mathrm{yref0}$. (b) plane rake faced twist drill with $30^{\circ}$ yrefo. 


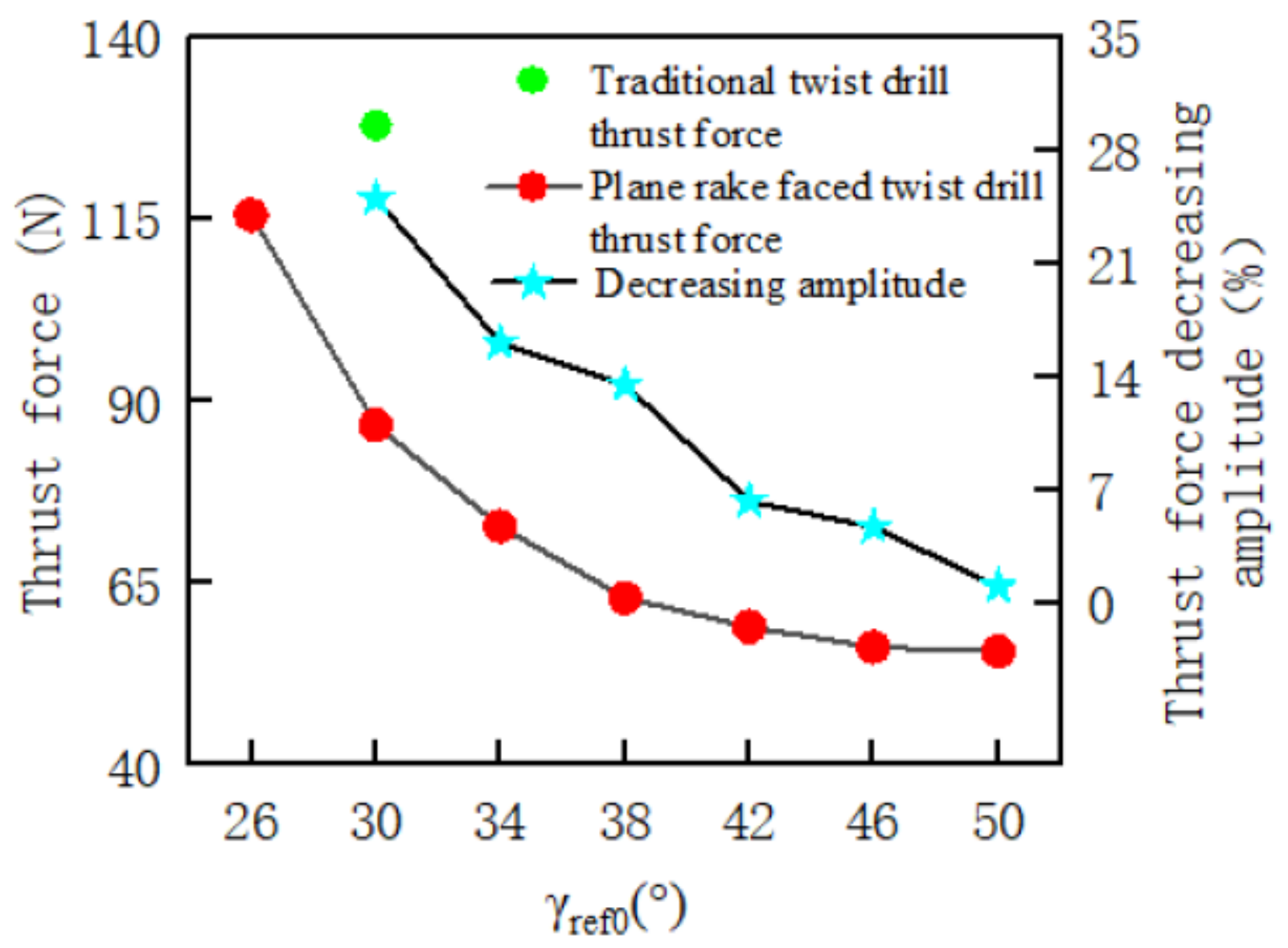

Figure 8

Thrust force values and decreasing amplitude with different plane rake faced twist drills. 


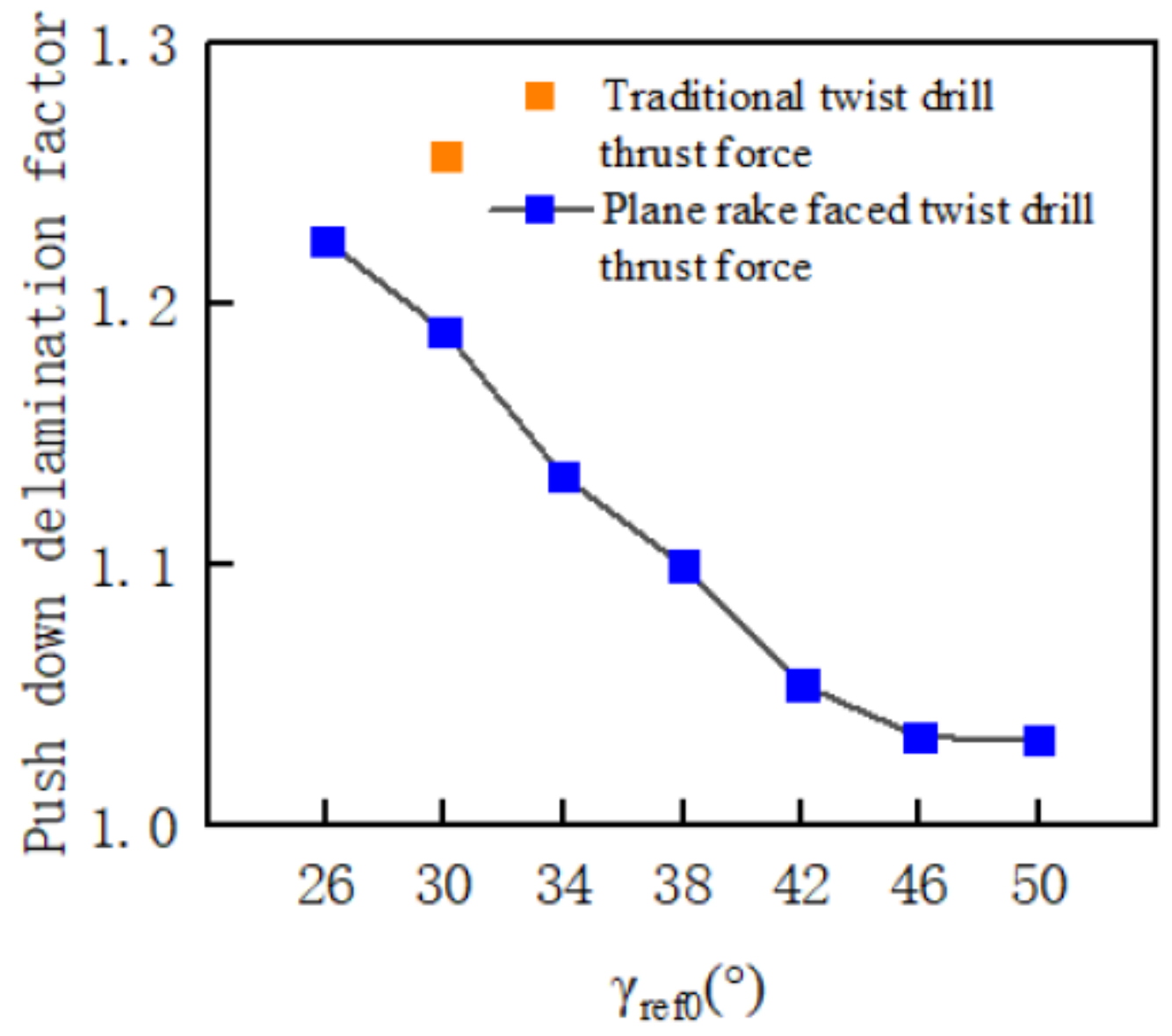

Figure 9

Push down delamination factors with different plane rake faced twist drills. 


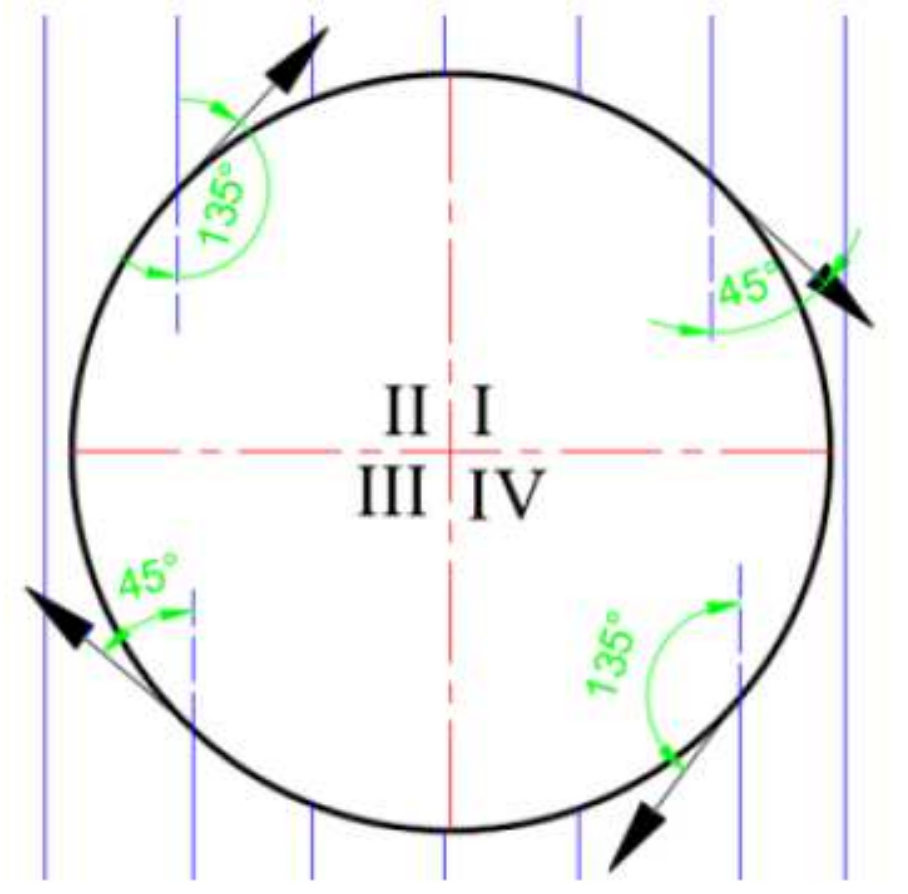

(a)entrance

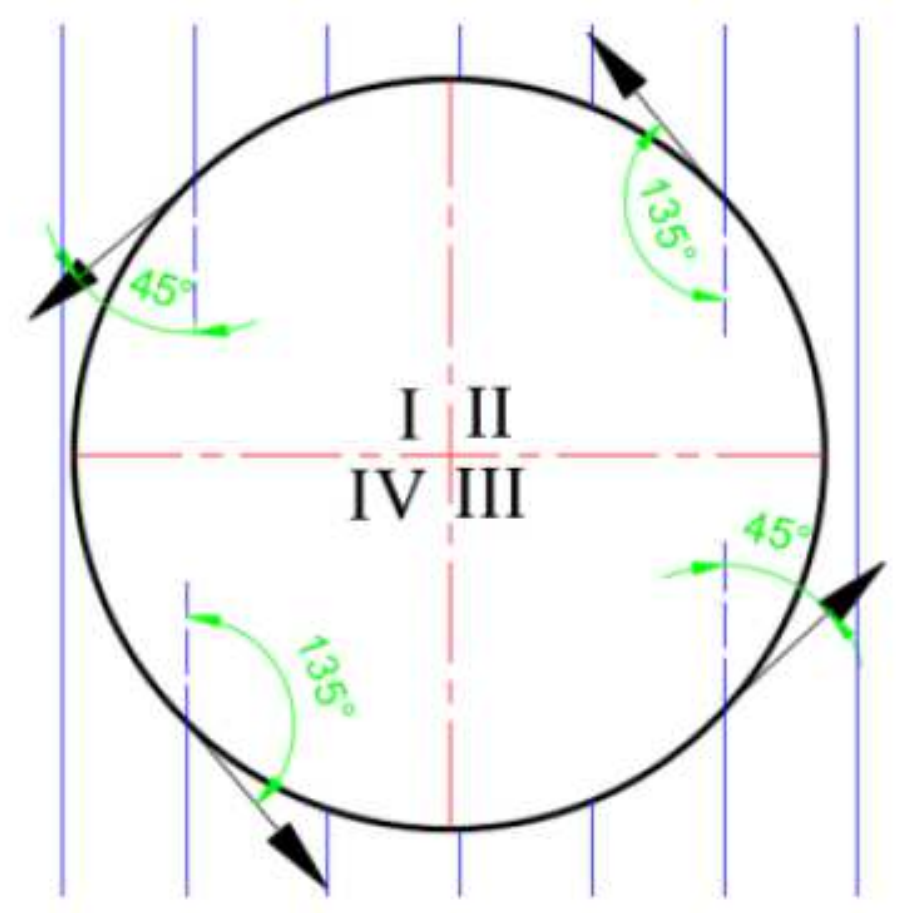

(b) exit

Figure 10

Definition of fiber cutting angle 


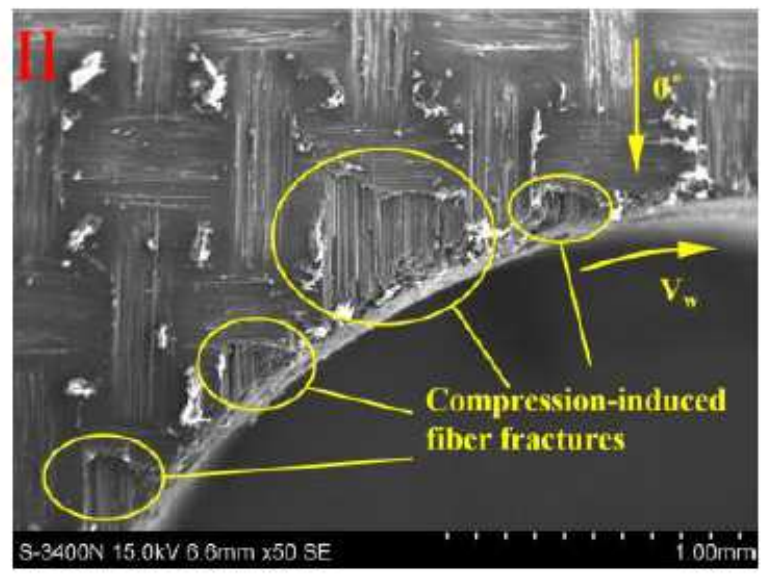

(a) $26^{\circ}$ against fiber cutting region

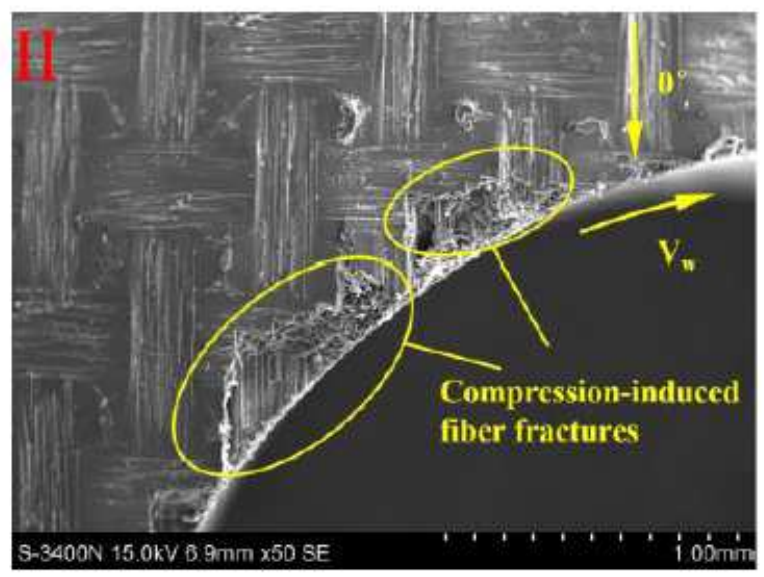

(c) $42^{\circ}$ against fiber cutting region

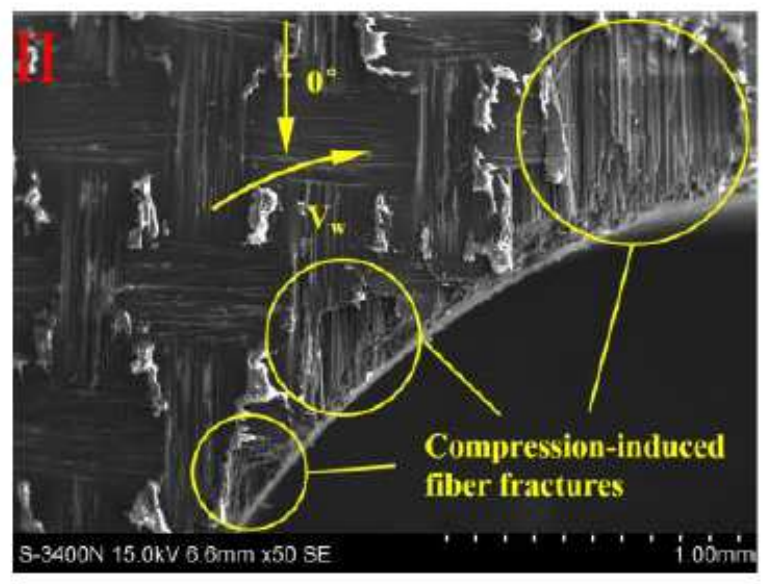

(e) $50^{\circ}$ against fiber cutting region

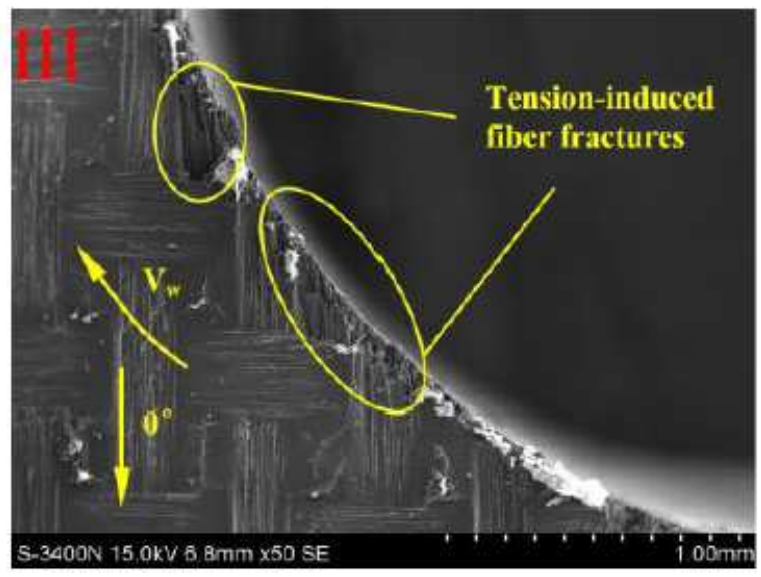

(b) $26^{\circ}$ along fiber cutting region

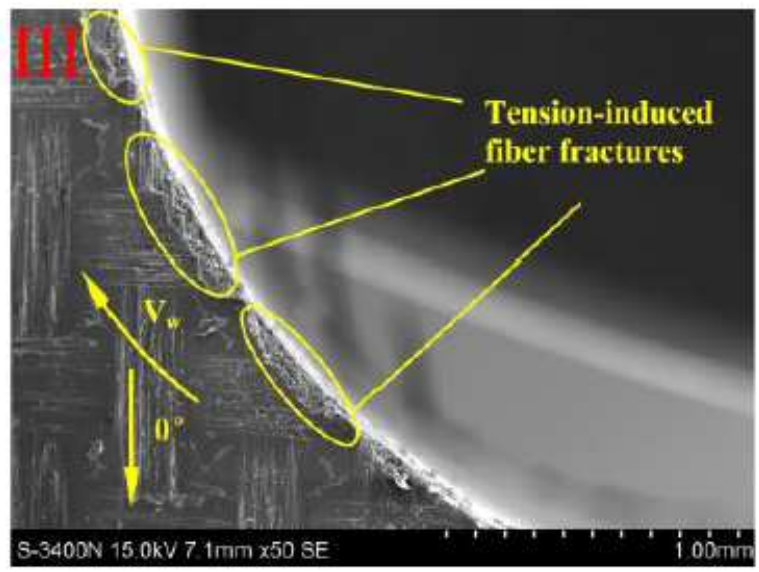

(d) $42^{\circ}$ along fiber cutting region

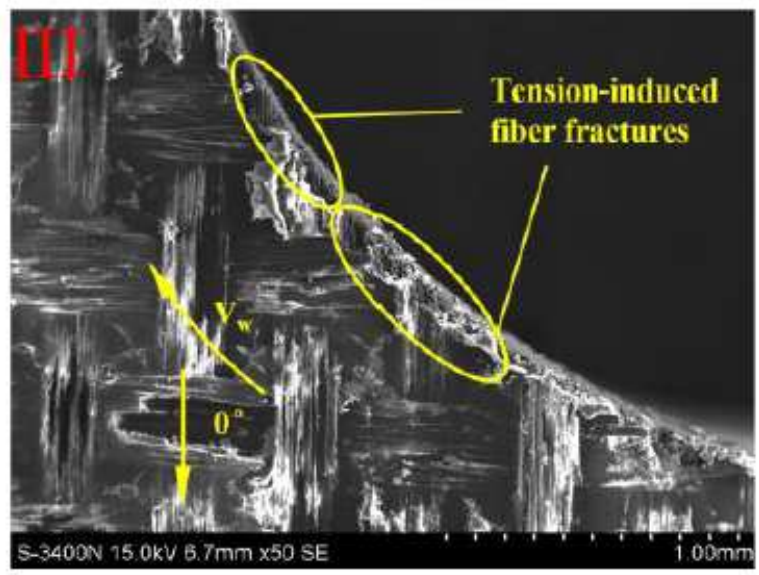

(f) $50^{\circ}$ along fiber cutting region

\section{Figure 11}

Micro morphology at the entrance surface of drilling hole. 


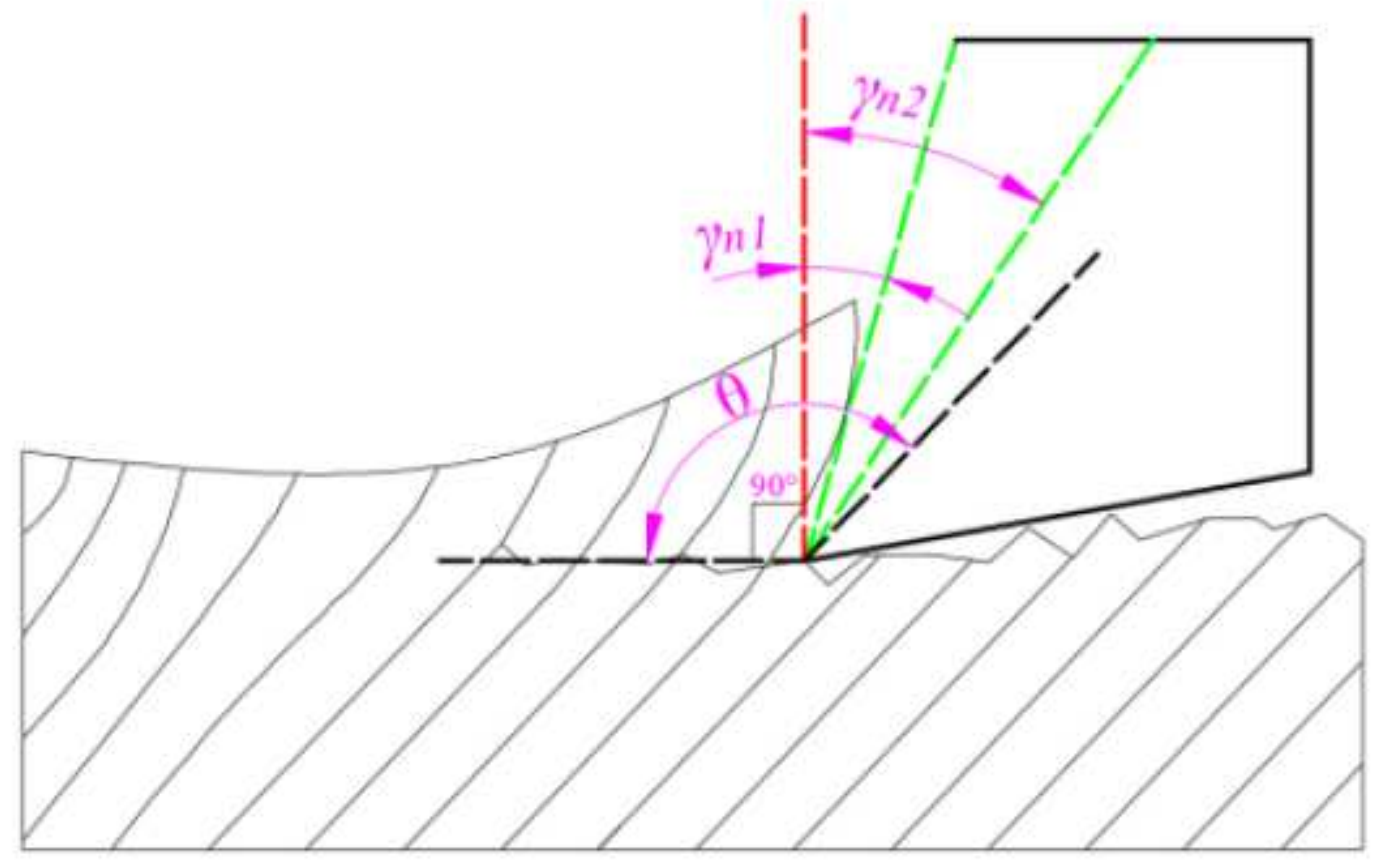

Figure 12

Diagrammatic sketch of cutting with different rake angles

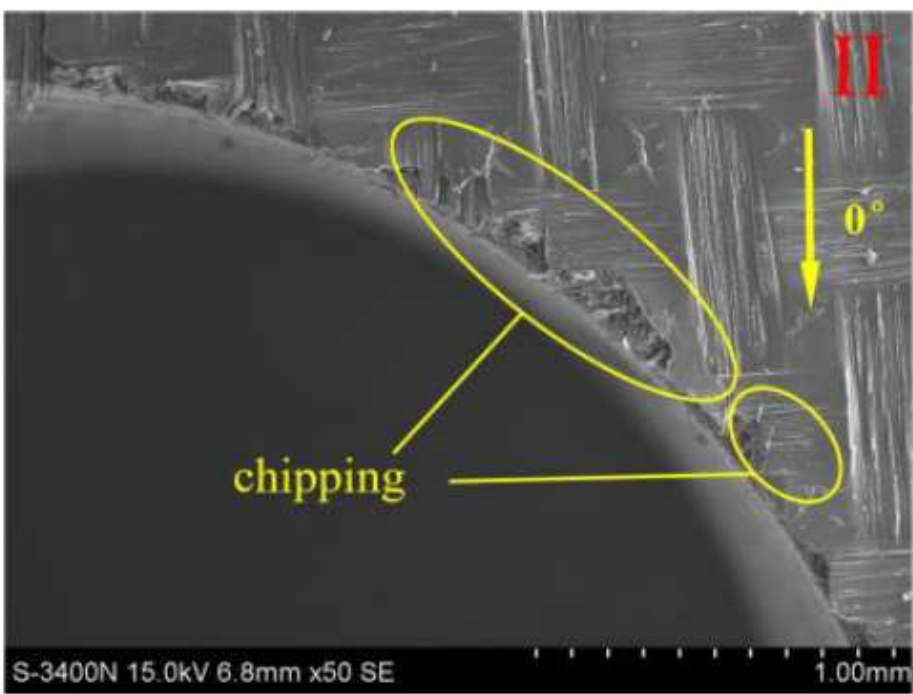

(a) $38^{\circ}$ against fiber cutting region

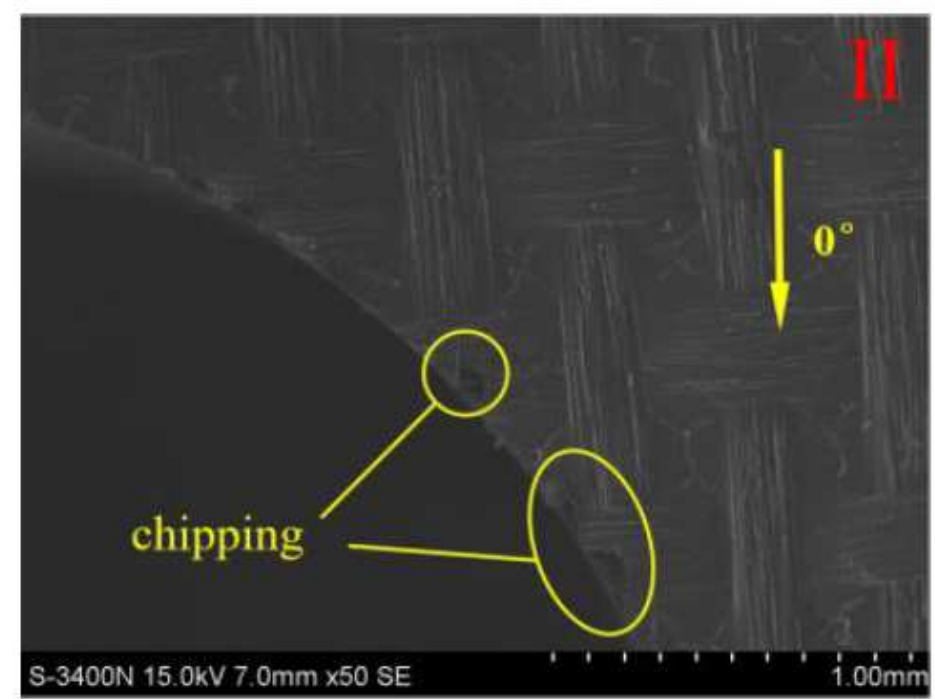

(b) $46^{\circ}$ against fiber cutting region

\section{Figure 13}

Micro morphology at the exit surface of tool drilling hole. 


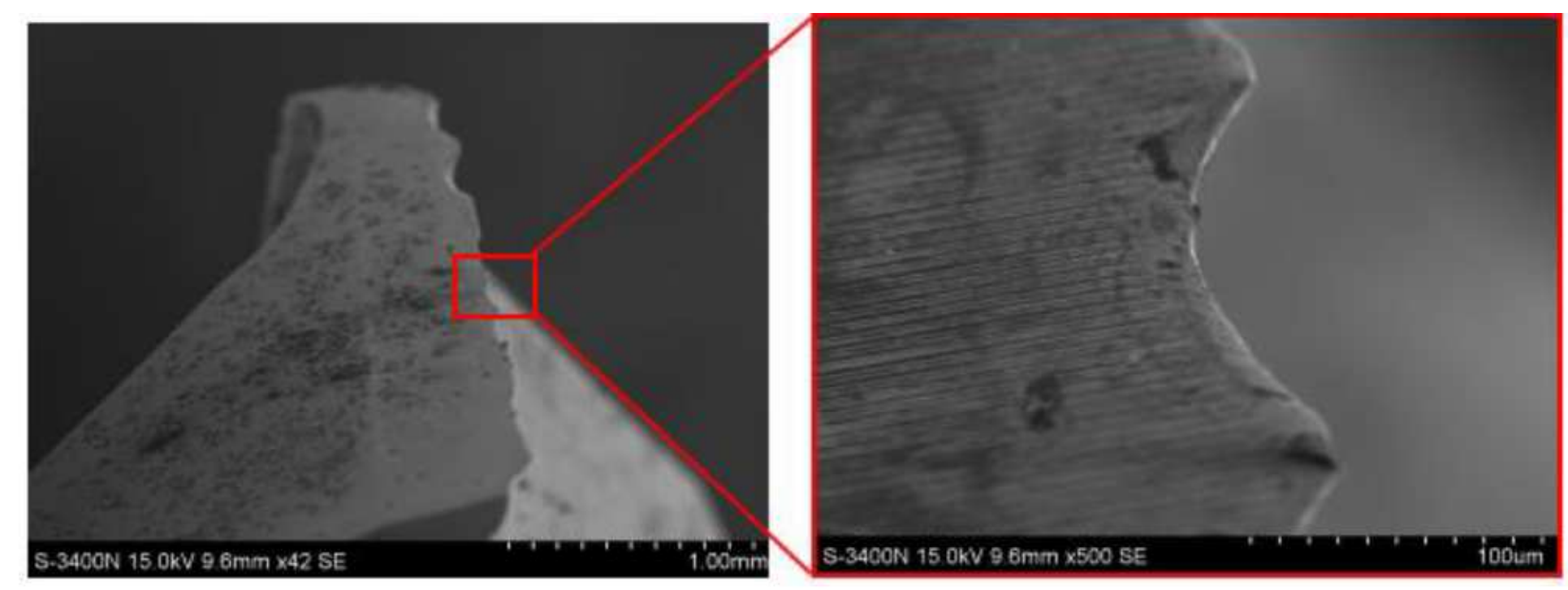

\section{Figure 14}

Micro morphology tipping of too

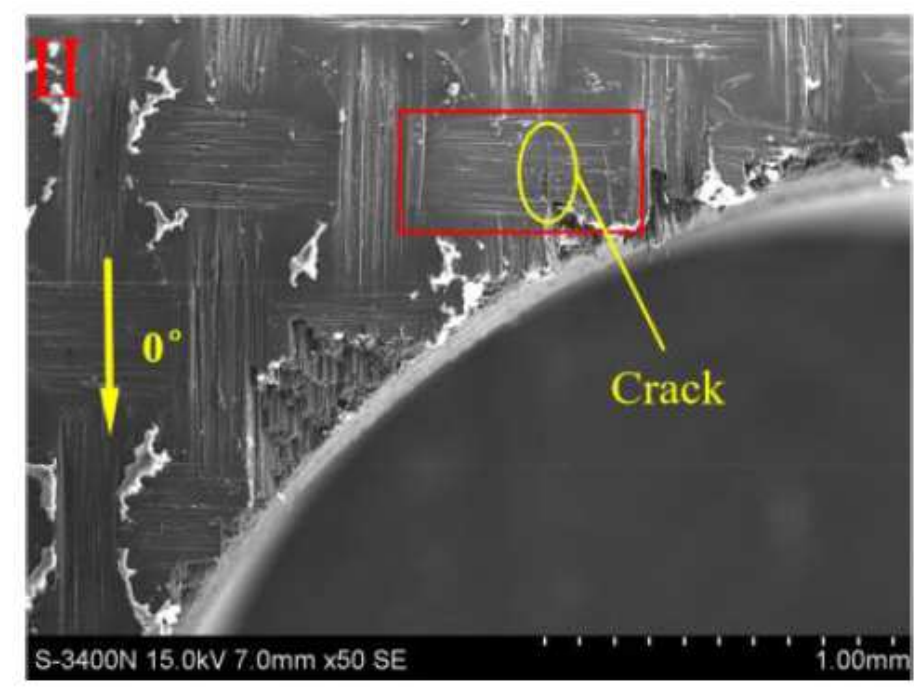

(a) $30^{\circ}$ against fiber cutting region

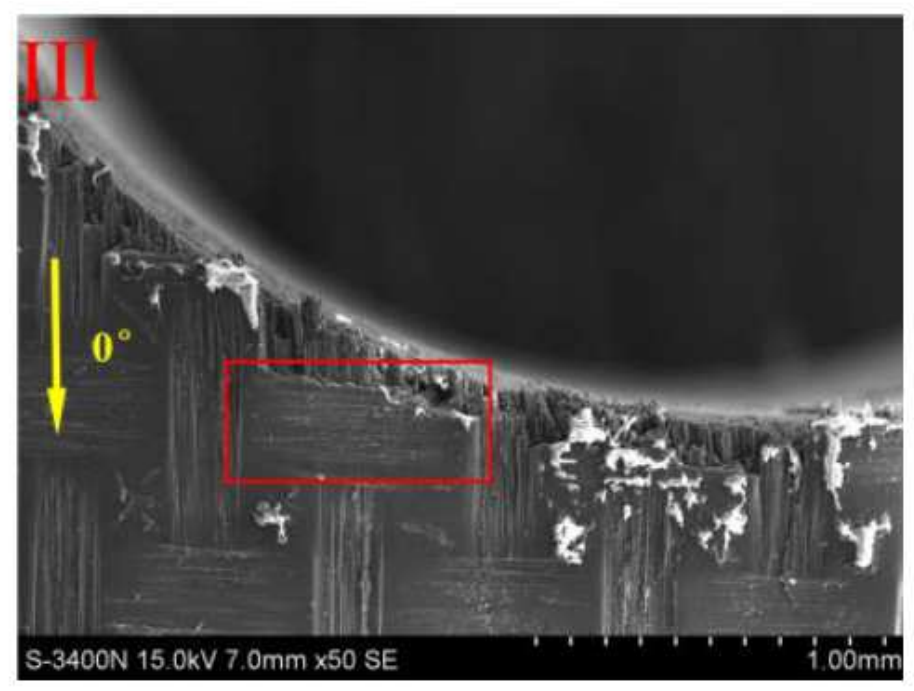

(b) $30^{\circ}$ along fiber cutting region

\section{Figure 15}

Micro morphology at the entrance surface of $30^{\circ}$ tool drilling hole. 


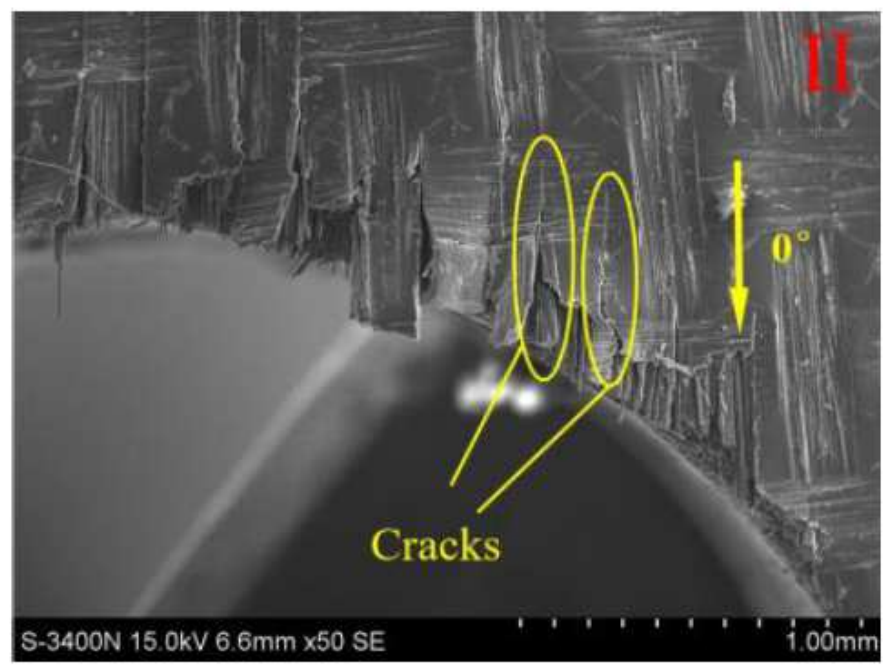

(a) $30^{\circ}$ against fiber cutting region

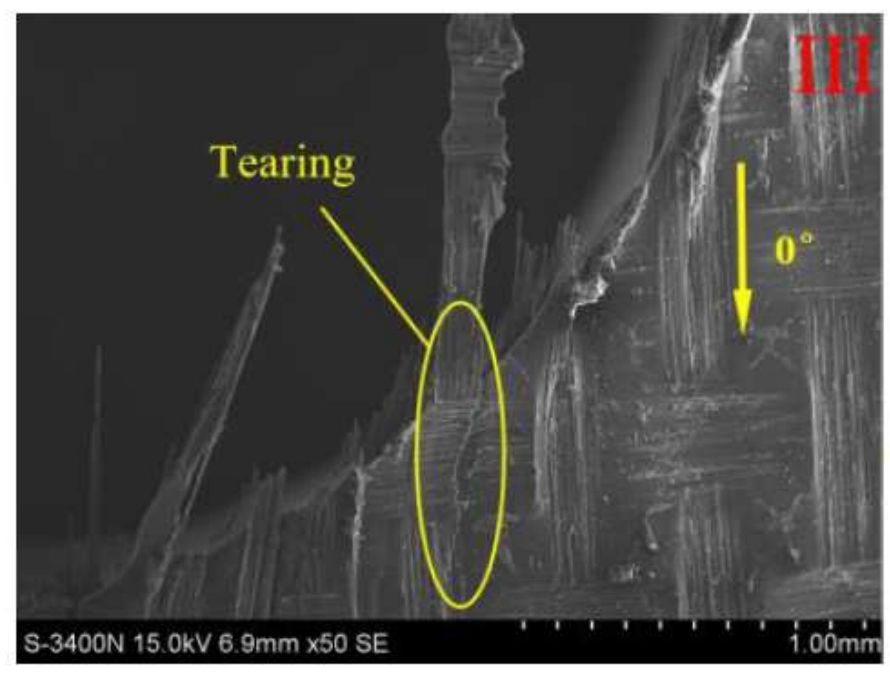

(b) $30^{\circ}$ along fiber cutting region

Figure 16

Micro morphology at the exit surface of tool drilling hole 